\title{
Exploring the Challenges of Social Integration within an Upper- Level Public Relations Classroom
}

\author{
Tabitha Hayley Dyer \\ thd0001@mix.wvu.edu
}

Follow this and additional works at: https://researchrepository.wvu.edu/etd

Part of the Adult and Continuing Education Commons, Gender, Race, Sexuality, and Ethnicity in Communication Commons, Interpersonal and Small Group Communication Commons, Journalism

Studies Commons, Public Relations and Advertising Commons, and the Women's Studies Commons

\section{Recommended Citation}

Dyer, Tabitha Hayley, "Exploring the Challenges of Social Integration within an Upper-Level Public Relations Classroom" (2020). Graduate Theses, Dissertations, and Problem Reports. 7523.

https://researchrepository.wvu.edu/etd/7523

This Thesis is protected by copyright and/or related rights. It has been brought to you by the The Research Repository @ WVU with permission from the rights-holder(s). You are free to use this Thesis in any way that is permitted by the copyright and related rights legislation that applies to your use. For other uses you must obtain permission from the rights-holder(s) directly, unless additional rights are indicated by a Creative Commons license in the record and/ or on the work itself. This Thesis has been accepted for inclusion in WVU Graduate Theses, Dissertations, and Problem Reports collection by an authorized administrator of The Research Repository @ WVU. For more information, please contact researchrepository@mail.wvu.edu. 
Graduate Theses, Dissertations, and Problem Reports

2020

Exploring the Challenges of Social Integration within an UpperLevel Public Relations Classroom

Tabitha Hayley Dyer

Follow this and additional works at: https://researchrepository.wvu.edu/etd

Part of the Adult and Continuing Education Commons, Gender, Race, Sexuality, and Ethnicity in Communication Commons, Interpersonal and Small Group Communication Commons, Journalism Studies Commons, Public Relations and Advertising Commons, and the Women's Studies Commons 
Exploring the Challenges of Social Integration within an Upper-Level Public Relations Classroom

Tabitha H. Dyer

Thesis submitted to the

Reed College of Media

at West Virginia University

in partial fulfillment of the requirements for the degree of

Master of Science in

Journalism

Jasper C. Fessmann, Ph.D., Chair

Jennifer L. Harker, Ph.D.

Dana Coester, M.A.

Lisa M. Dilks, Ph.D.

Department of Journalism

Morgantown, WV

2020

Keywords: Public Relations, Public Relations Education, Grounded Theory, Gender Studies, Qualitative Study, Undergraduate Students, Role Congruity Theory, Tokenism, Nurse Education, STEM Education

Copyright 2020 Tabitha Dyer 


\section{ABSTRACT \\ Exploring the Challenges of Social Integration within an Upper-Level Public Relations Classroom}

\section{Tabitha H. Dyer}

Despite three decades of literature that has explored the gender imbalance of public relations at a professional level, there is a dearth of information addressing if or how these experiences are informed at a collegiate level. Accordingly, this study examines if the gender imbalance impacts students in the upper-level public relations classroom, and the similarities and differences exist between other single-gender dominant programs including nursing and Science, Technology, Engineering, and Mathematics (STEM) using three dimensions (i.e., role strain, teamwork, and overall social environment) as a comparison. Using qualitative in-depth interview data collected from 13 junior- and senior-standing public relations students from a large, mid-Atlantic university, this study found themes including female-to-female reliance, female-to-female competitiveness, female leadership, perceived low male work ethic, male humor, and siblings and comfort with the opposite sex. The findings suggest that upper-level public relations students do encounter social challenges because five of the 10 challenges are related to the phenomena experienced by upper-level public relations students. These findings were unique to other singlegender dominant programs in that three were similar to tokenism in addressing academic excellence, loneliness, humor, and independence in group work. Two of the findings were different because they addressed traditional roles and leadership which is consistent with role congruity theory. With this, it is asserted that the challenges experienced by upper-level public relations students are most applicable to tokenism and bridging collegiate to professional challenges is addressed in role congruity theory. 


\section{DEDICATION}

I want to dedicate this to my great-grandmother, Zoila Santos (1920-2015), who had love and support with no bounds. I know she watches over me every step of the way, and would be so proud to watch me on my academic journey. 


\section{ACKNOWLEDGEMENTS}

I would like to thank my committee chair, Dr. Jasper Fessmann for guiding me through my initial concepts to address student experiences, which led to the thesis presented. I want to thank my committee members, Dr. Jennifer Harker for her helping me decide my future Ph.D. path, Professor Dana Coester for her passion in addressing the gender gap in media, and Dr. Lisa Dilks for her expertise in women and gender studies.

I want to thank Dr. Julia Fraustino, who during my first year of graduate school helped me transition from strategic communication to academic writing. With repeated reading and writing practice, her help and patience motivated me to continue my study.

I want to thank my mom, Deborah Dyer for her love and support through my academic journey. For my fiancée, Jeffrey Kinneer who spent countless hours as I explained my successes, failures, and trying times in the process of my thesis development. Hopefully by now, you have learned as much as I have about academic research throughout my time in the program.

I want to sincerely thank the study participants as this would not be possible without you. 
TABLE OF CONTENTS

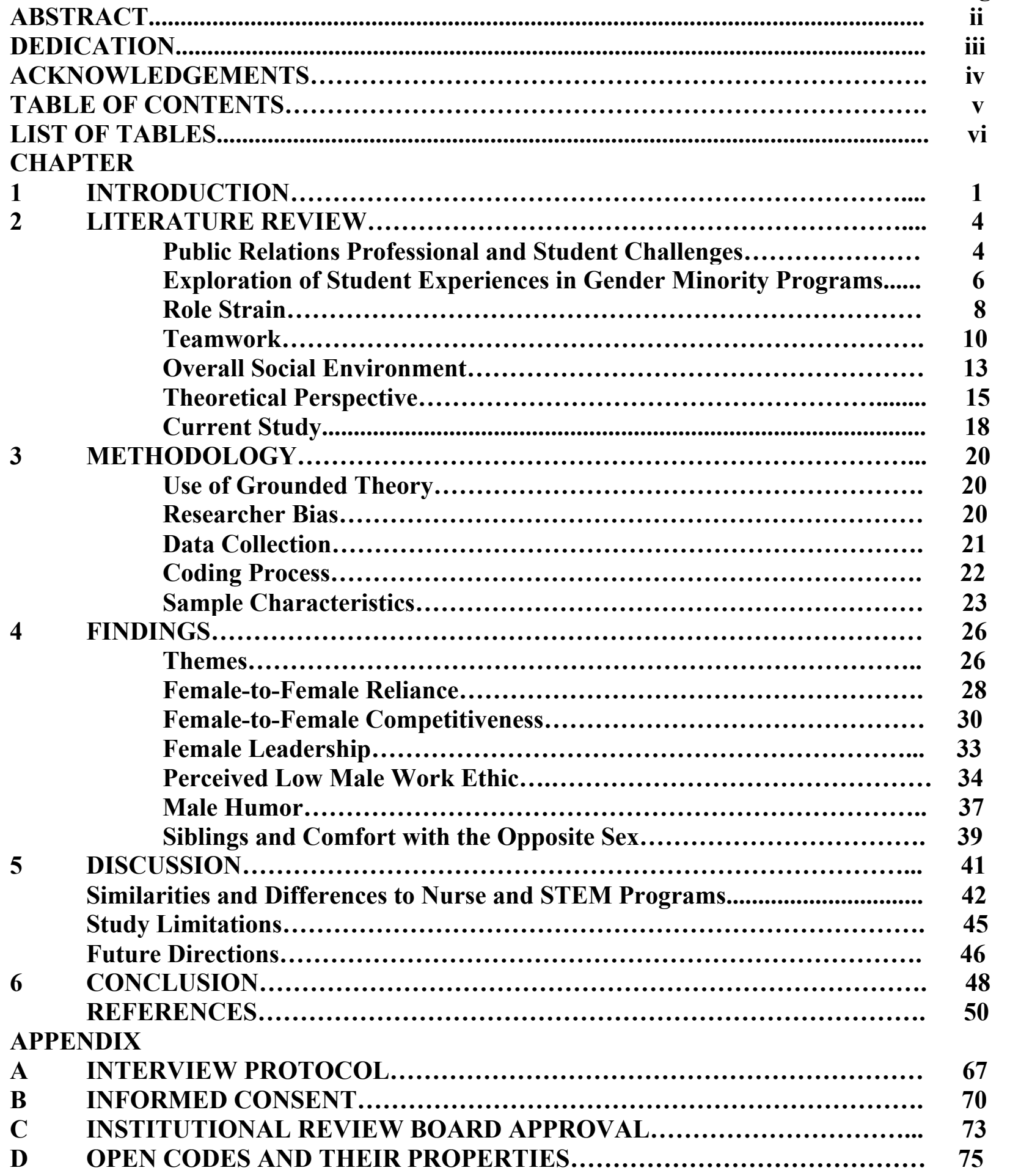




\section{LIST OF TABLES}

Table 1

Participant Demographics..................................... 25

Table 2

Themes.

26 


\section{CHAPTER 1 INTRODUCTION}

Men and women have been involved in public relations since its inception (Watson, 2016). Yet, maintaining an equal gender distribution within the academic and professional setting has been a significant battle for decades. At the start of World War II, women transitioned from working in the household to occupying roles such as public relations (Horsley, 2009; Krugler, 2017; Wright \& Flynn, 2017). Post-war, men returned to their previous roles, and women diminished in the field, as the stereotypical portrayals in the media hindered their retention (Tuchman, 1979; Watson, 2016; Krugler, 2017). Cline (1986) reported that females represented 3.8\% of incoming Public Relations Society of America (PRSA) members between 1949 and 1952 (Long, 2011). As such, women advocated equal membership, as the male-dominated organization also held conventional messages of women in the field (Gower, 2017). It was not until the 1970s when the shift of male employment declined rapidly, as females entered the professional setting (Reskin, \& Roos, 1990; Long, 2011).

Today, female public relations professionals account for over approximately $70 \%$ of the industry (The Holmes Report, 2015; Shah, 2015; Allen, 2016; BLS, 2019). Even in communication and public relations organizations, females comprise $75 \%$ of PRSA members (PRSA, 2019, p. 3). Scholars have created three decades worth of knowledge dedicated to how gender diversity has impacted the public relations field (Toth, Aldoory, \& Sha, 2006; GeyerSemple, 2012; Vardeman-Winter \& Place, 2017). Despite a significant amount of literature that documents social challenges that exist for professionals, there is a dearth of information surrounding the experiences of public relations students during college. Similar to the industry, female student enrollment in public relations programs and student organizations are substantially higher than males. Females comprise the majority of public relations majors as well as the national Public Relations Student Society of America (PRSSA) membership by nearly 90 percent of the members' demographics (Martin, 2008; Long, 2011). Recent studies suggest that gender imbalance negatively affects male public relations students' perception of the classroom environment.

A Waymer, Brown, Baker, and Fears (2018) study showed gendered social challenges affect entry-level male professionals during college. Individually, they felt less integrated with 
the class and desired a more significant male presence. Similarly, junior- and senior- standing male undergraduate students perceived a lack of inclusivity and overall lower positive outcomes in the course than their female peers (Brown, Waymer, \& Zhou, 2019). As studies suggest the issue does exist, subsequent research is needed to understand how public relations students experience social challenges, specifically in their interactions with their peers. Previous studies support that social interactions are critical, as they can determine student success in completing the program as well as establishing the social dynamics within the industry.

The public relations field is not alone in this, like other fields and programs such as nursing (female-dominant) and Science, Technology, Engineering, and Mathematics (STEM) (male-dominant) scholars have found social challenges to occur in other single-gender dominant programs.

Nursing and STEM education literature have addressed social challenges which occurred within three dimensions, including role strain (e.g., externalities from gender identity) which has shown to impact the perception of identity, gender stereotyping, and the desire to work harder in minority students (Dingel, 2006; Dyck et al., 2009; Eddy \& Brownell, 2016; Posselt \& Lipson, 2016; Lewis et al., 2017), teamwork (e.g., student-to-student group communication) which has shown themes relating to loneliness, tokenism, and leadership (Dingel, 2006; Dyck et al., 2009; MacWilliams, 2013; Hodges et al., 2017; Carter et al., 2019), and overall social environment (e.g., classroom discussions and activities) which included contributions, male humor, and dissent (Dyck et al., 2009; Kanack, 2011; MacWilliams, 2013; Eddy \& Brownell, 2016). These dimensions will be used to determine if and how public relations students experience social challenges within the classroom environment using a variety of findings to identify specific challenges.

Understanding the impact of the gender imbalance is crucial, as a students' sense of belonging can influence their "health, social adjustment, and well-being" (Baumeister \& Leary, 1995; Sedgwick \& Kellett, 2015, p. 122). Social interactions can also affect their decision to complete the program as well as continue with graduate studies (Astin \& Sax, 1996; Morris, 2007; Gayles \& Ampaw, 2014). It should be noted that college interactions can also transition into social dynamics within the field, including interactions with colleagues (Levett-Jones, Lathlean, Maguire, McMillian, 2007). By understanding the impact the gender imbalance has on public relations students as well as the similarities and differences from nursing and STEM 
education literature can provide better insight to improving the quality of student social learning outcomes in the classroom. Accordingly, this study examines if the gender imbalance impacts students in the upper-level public relations classroom, and the similarities and differences exist between other single-gender dominant programs including nursing and Science, Technology, Engineering, and Mathematics (STEM) using three dimensions (i.e., role strain, teamwork, and overall social environment) as a comparison. 


\section{CHAPTER 2}

\section{LITERATURE REVIEW}

\section{Public Relations Professional and Student Social Challenges}

For over thirty years, the scope of literature on gender inequality is concentrated within the professional realm (Toth, Aldoory, \& Sha, 2006; Geyer-Semple, 2012; Vardeman-Winter \& Place, 2017). Multiple professional studies addressed social challenges related to gender, including traditional roles (Fitch, James, \& Motion, 2016; Krugler, 2017; Place \& VardemanWinter, 2018), stereotypes (Toth et al., 2006; Peters \& Froelich, 2006), discrimination (Smith, 2005; Toth et al., 2006; Long, 2011), and a lack of female representation in leadership (Long, 2011; Krugler, 2017; Place \& Vardeman-Winter, 2018). A participant from Long's (2011) study described the lack of practitioner diversity in the field, "gender imbalance is PR's dirty little secret [and it] has never been as diverse or as inclusive as we want it to be" (p. 67).

As the female student enrollment in public relations programs and student organizations is also substantially high, the gender imbalance is also apparent at the collegiate level. Long (2011) noted that since the mid-1990s, females remain the dominant gender within public relations major enrollment (Grunig, Toth, \& Hon, 2001; Fuller, 2010).

Several scholars have also noted that the challenges of the gender imbalance may occur at the college-level and recommend subsequent studies to understand this further (Pompper \& Jung, 2013; Place \& Vardeman-Winter, 2018; Waymer, Brown, Baker, \& Fears, 2018). Recently, the lack of gender diversity has shown to affect young professionals as they transitioned from college to the workforce. Waymer et al. (2018) showed gendered social challenges to affect entry-level professionals during college. They found that 12 out of 24 practitioners felt gender affected their learning. Waymer et al. (2018) noted that a male practitioner stated, "I feel like we are often alienated. I have witnessed female colleagues intentionally leave out top-tier male students due to our gender. As a male, I felt as if I was discriminated against [in the classroom]" as he reflected on his academic experiences (Waymer et al., 2018, p. 125). Brown, Waymer, and Zhou (2019) added that junior and senior standing undergraduate male students perceived a lack of inclusivity, opportunities for leadership, and overall lower positive outcomes in courses than females. As recent studies suggested gendered social challenges exist, subsequent research is needed to understand how public relations students interact with their peers. Previous studies 
support that social interactions are critical, as they can determine student success in completing the program as well as influencing industry social dynamics.

Scholars have noted that male and female students' social experiences determine their decision to complete the program and pursue graduate programs (Astin \& Sax, 1996; Gayles \& Ampaw, 2014). Eddy, Brownell, and Wenderoth (2015) noted that instructor and peer interactions are critical, "factors external to a student, such as how they are treated by those around them" that lead to their decision to change their career path or drop out of the program (Morris, 2007; p. 3). Similarly, the rate of degree completion was related to students' perception of isolation (Stott, 2007; Sedgwick \& Kellett, 2015). A student with a lower sense of belonging in the community has shown detrimental effects on their "health, social adjustment, and wellbeing” (Baumeister \& Leary, 1995; Sedgwick \& Kellett, 2015, p. 122). Social interactions are influential to students in that they can impact their success while completing their degrees.

These challenges are also shown to translate post-graduation, where it affects job satisfaction and interactions with colleagues (Levett-Jones, Lathlean, Maguire, McMillian, 2007). College can also set the tone for professional environments. Garibay (2015) stated that student interactions with faculty and students created a fixed social "culture and value" of the program (Garibay, 2015, p. 445). The social culture can influence the gender minority students in completing both undergraduate and pursing graduate degrees, as a status that excludes them may deter their success (Blickenstaff, 2005; Gillen \& Tanenbaum, 2014; Eddy \& Brownell, 2016). As other academic fields have found, social experiences impact the retention and success of students and college programs also develop a social norm that can follow into the professional realm.

As professional and recent college studies suggest that gendered challenges present an issue in the classroom social environment, this study aims to understand how public relations students' experiences are interacting with their peers. Focusing on the educational aspect is essential as it can influence the status of the professional realm, "public relations education is a step towards the necessary change in the profession, given that students are tomorrow's professionals" (Muturi \& Zhu, 2019, p. 83-84). Understanding if and how public relations students experience these adversities can provide insight into improving their quality of learning and retention of gender minority groups. 


\section{Exploration of Student Experiences in Gender Minority Programs}

As public relations education focused on if gendered social challenges occur remains relatively unexplored, findings from other alike fields may provide insight to both the academic and professional consequences. This study seeks to determine how the gender imbalance impacts upper-level public relations students, and what similarities or differences exist between other single-gender dominant programs, such as nursing and STEM. A male- (STEM) and female(nurse) dominant programs will be used as they indicate the spectrum of gendered challenges for both minority group members. It should be noted that in identifying challenges for male public relations students, scholars identify this with nursing programs (Cline et al., 1986; Long, 2011; Pompper \& Jung, 2013). Additionally, the literature showed that female STEM students experienced similar adversities in their academic environments.

Within nursing programs, male students undergo a myriad of social challenges in interacting with their faculty and peers. Male nurses comprise $10 \%$, which is lower than male public relations professionals, with 36.4\% within their respective fields (AACN, 2015; BLS, 2019). While females dominate in life sciences, males comprise the majority of members in other Science, Technology, Engineering, and Mathematics (STEM) programs (National Science Foundation, 2011; U.S. Department of Education, 2012; Wang \& Degol, 2017). Except for the social sciences, females in the STEM field constitute $1.3 \%$ of physical sciences, $10.3 \%$ of mathematics/statistics, and 12.2\% computer science of all earned bachelor's degrees (NCSES, 2016). Accordingly, both nurse (AANC, 2015; Abshire et al., 2018; BLS, 2019) and STEM scholars (Eddy, Brownell, Thummaphan, Lan \& Wenderoth, 2015; Eddy \& Brownell, 2016; Carter, Dueñas \& Mendoza, 2019) have explored the consequences of gender minority status within both the educational and professional settings in an attempt to diversify the marginalized status.

Nursing education literature has identified how both male and female students experience social obstacles in class and clinical-space environments. Using primarily qualitative methodologies (i.e., ethnographic, phenomenology, in-depth interviews), scholars have found male students have experienced gender stereotypes (Bartfay, Bartfay, Clow, \& Wu, 2010; Meadus \& Twomey, 2011; Rajacich, Kane, Williston, \& Cameron, 2013), the feeling of isolation or loneliness (IOM, 2010; Meadus \& Twomey, 2011; Sayman, 2014), and gender discrimination as a result of the female-dominated learning environment (Meadus \& Twomey, 2011; Rajacich et 
al., 2013). Likewise, STEM education literature has also described how gendered experiences have shaped students' social interactions. While the majority of methodologies focused on quantitative and mixed methods (i.e., surveys and in-depth interviews), studies showed that female students also experienced gender stereotypes (Eddy \& Brownell, 2016; Wang \& Degol, 2017; Carter et al., 2019), loneliness (Dingel, 2006; Carter et al., 2019), and gender discrimination (Wang \& Degol, 2017; Carter et al., 2019). In both fields, it was also apparent that gender minority students were more likely to drop out of their programs as a result (Dingel, 2006; Stott, 2007; Tosh-Kennedy, 2007; Eddy \& Brownell, 2016; Sedgwick \& Kellett, 2015). This study will incorporate qualitative methods because (a) nursing programs have been identified as a reference to public relations education (Fitch \& Third, 2010; Pompper \& Jung, 2013) and (b) research on gendered social challenges is relatively new and will require more insight into how this occurs for public relations students.

The differences in both fields are minor, as the enrollment of males in nursing $(10 \%)$ is slightly lower than all females enrolled in STEM majors (AANC, 2015; NCSES, 2015). Also, as the nursing program often requires hands-on clinical training, student experiences also occur in the work environment, similar to a licensed practitioner (MacWilliams et al., 2013; Hodges et al., 2017). Despite this, both programs can be used to determine the similarities and differences between public relations students social learning outcomes.

Understanding the gendered social consequences students encounter is critical because it has shown to be detrimental to their success. As Wang \& Degol (2017) explained, the disadvantages experienced such, as "sexism and gender bias" become second nature in the classroom environment, and later become a permanent status (p. 127). Historically, public relations has dealt with gender inequality for decades, and the consequences found from this may be a prelude to classroom social outcomes. As Muturi \& Zhu (2019) stated, this includes both faculty and student interactions, which may occur the most in the classroom environment. Wang and Degol (2017) also added, "these beliefs can influence the way in which individuals think, behave, and feel about their own abilities, in addition to the way in which they view others" which can reinforce gender discrimination which impacted minority students (p. 131). We must implement ways to prevent gender social adversities that have shown to impact student success and retention. Using reference to nursing and STEM students' experiences to examine the social 
challenges of public relations students is a necessary step to building a more diverse and equal future for incoming professionals and the industry.

As Long (2011) stated: “increasing our understanding of students' perceptions of work, life and gender issues in public relations is not only relevant but even critical to the survival of our field" as their educational experiences inform it (Sha, 2005, p. 99; Waymer et al., 2018). There are three types of social interactions that have unique themes that serve as a reference to the challenges public relations students face, including role strain (individual interactions), teamwork (student-to-student social interactions), and overall social environment (activities that comprise of the instructor and student interactions). There are 10 total social challenges that occur across all dimensions.

\section{Role Strain}

One of the recurring themes of single-gender dominant programs is how student interactions with faculty and peers influence their ability to succeed. Namely, a students' perceived higher expectations that influence their coursework and classroom activity engagement, also known as role strain. Role strain exists as part of daily functions within social environments, such as college (Lupton, 2000). Within the setting, traditional roles such as masculine and feminine behaviors can become modified and latter fixed as people adjust in social contexts (Eagly \& Steffen, 1984; 1986; Eagly, 1987; Jackson \& Sullivan, 1990; Collinson and Hearn, 1994; Lupton, 2000). As members of the program solidify these held concepts, they create a structure that becomes representative of the program and the following field (Geis, 1993; Ridgeway \& Erikson, 2000; Eagly \& Diekman, 2004). It can become consequential, as roles create an invisible barrier that discourages inclusivity (Witz, 1992; Lupton, 2000), challenges to their identity, tone down their behaviors, or lead to assimilation in an attempt to blend into the environment (Glick, 1991; Judd \& Oswald, 1997; Lupton, 2000; Diekman \& Goodfriend, 2004; Eagly \& Diekman, 2004; Dyck et al., 2009). Role strain encompasses “individual worries about meeting the numerous expectations associated with multiple roles or identities" (Goode, 1960; Edwards, 2014; Posselt \& Lipson, 2016, p. 976). The examination of student role strain aims to understand if upper-level public relations students experience role strain, and what similarities or differences exist between nursing and STEM students in this aspect. In this aspect, male nursing 
and female STEM students share three challenges that address gender stereotyping and identity, masculinity, and academic performance.

First, male nursing students undergo several challenges that may influence their ability to work efficiently. Men enrolled in nursing programs are often stereotyped as homosexual (Dyck et al., 2009). While males in STEM did not face sexual stereotyping, female students felt the degree to which they associate with their female identity impacted their alignment in their programs (Cundiff et al., 2013; Eddy \& Brownell, 2016). As a result, student identity may cause role strain, as males may focus on maintaining their sexual identity or an identity dedicated to their respected STEM field for females.

Second, male nursing students face social stigma as they are asked to tone down masculine attributes such as "competitiveness or assertiveness," as an example, to "avoid sanction" from faculty and peers (Wilson, 2005; Dyck et al., 2009, p. 650). However, for female STEM majors, their classroom environment is overridden with masculinity, which, in turn, may cause turmoil in working with their peers (Cheryan et al., 2009; Cheryan et al., 2015; Master et al., 2016; Lewis et al., 2017). Seymour (1995) found that female students faced verbal sexual harassment, were less likely to be taken seriously, and scrutinized if they were more academically successful by their male peers (Fencl \& Scheel, 2006). As a result, they must learn to adapt to an environment that challenges their success as female students (Seron et al., 2018; Carter et al., 2019). For males in a female-dominant program, they may be more focused on avoiding social stigma from instructors, while females in a male-dominant program may face challenges in trying to maneuver unfair treatment from their peers.

Third, male students believe they must outperform within the classroom setting as they are "scrutiniz[ed] more closely" by instructors (Kelly et al., 1996; Anthony, 2004; Dyck et al., 2009 , p. 650). Females in STEM also feel they must academically perform strongly to be successful. For example, Dingel (2006) found that they may focus on their grades (i.e., assignments and homework) to exemplify their excellence in the course material (Kubanek \& Waller, 1996; Seymour \& Hewitt, 1997). Female students also seek "affirmation" even as far as dedicating additional time to their coursework, including attending more office hours (which was not explicitly found for male nursing students) than their male peers (Kanter, 1977; Dingel, 2006, p. 163). The greater focus on excellence in these areas creates a challenge as it could impact retention, "even minor failures may seem huge to these women and they may interpret 
grades that are by most standards good (such as a B) as not good enough and therefore a sign that they should not be in science" (Orenstein, 1994; Dingel, 2006, p. 173). Both groups experience similar pressures to be academically successful as a minority within their respected programs.

\section{Teamwork}

The public relations curriculum often involves student teamwork collaboration, which is beneficial as students are engaged in strategy development by brainstorming and making critical decisions in campaign design (Long, 2011). This classroom activity can be both positive and negative, a Long (2011) participant described teamwork challenges as "men can be more direct, less emotional in their actions and decision-making process. This is a great benefit in many situations and/or can sometimes be seen as rigid, less thought through. Women can sometimes read the room/situation and deploy diplomacy to navigate to a solution that satisfies many around the table" said an female agency president (p. 70). The examination of student teamwork aims to explore how gender imbalance impacts upper-level public relations students, and what similarities or differences exist between male nursing and female STEM students. In this context, student teamwork is "a distinguishable set of two or more individuals who interact independently and adaptively to achieve specified, shared and valued objectives" in classroom activities (Morgan, Salas, \& Glickman, 1993; Bravo, Lucia-Palacios, \& Martin, 2016, p. 303). Similarly, "teamwork may refer to the nature and quality of individual contributions to a team effort, adopting a process-oriented focus" in achieving the overall activity goal (Hughes \& Jones, 2011; Britton, Simper, Leger, \& Stephenson, 2017, p. 379).

This study will examine the responsibilities and interactions of group members in these activities. There are notable challenges of single-gender dominance in comparison to genderbalanced programs. Gender balanced programs have proven beneficial to students, including group strategy (Fenwick \& Neal, 2001), perceived self-efficacy (Bear \& Woolley, 2011; Lee \& Farh, 2004), and less stereotyping (Bear \& Woolley, 2011). Nevertheless, in single-gender dominant programs, having an unequal gender membership can present consequences, including in the group strategy (Rogelberg \& Rumery, 1996; Bear \& Woolley, 2011). As shown in male nurse and female STEM students, the literature addressed four challenges, including loneliness, team leadership, friendship, and independent or dependent performance. 
Classroom activities involving teamwork or collaboration, present another challenge to gender minority students. In examining STEM female and male interactions, Eddy et al. (2015) noted that "socialization differences... could lead to differences in students' perceptions of the value of peer discussions" and may impact student team activities (Kim, 2002, 2008; p. 14:ar45, 3). For example, in a female-dominated classroom, female students may be more accustomed to collaboration with other female peers, causing challenges for male input. MacWilliams et al. (2013) found that male nursing students "experienced loneliness and isolation" in their program outcomes, which may be apply to student group activities (Kelly et al., 1996; p. 41). Despite more studies showing this as an externality for male nurses, it was also shared by female STEM students (IOM, 2010; Meadus \& Twomey, 2011; Sayman, 2014). For female STEM students, their team projects involved a lack of enriching activities that were offered to males in the classroom. Carter et al. (2019) stated that "men are routinely given more challenging activities (e.g., integrating theory into practice, solving more technical problems), while women are often assigned nontechnical, peripheral roles in a project of group setting" in their assigned work (Seron et al., 2018, p. 72). In this case, female students may feel less integrated, given easier responsibilities, and also felt expected to perform at a higher level, resulting in the perception of "isolation" from their peers (Cheryan \& Plaut, 2010; Wang \& Degol, 2017; Carter et al., 2019, p. 72). As both male nursing and female STEM students constitute the minority, they may seek relationships with other gender minority students if they encounter challenges forming meaningful relations with their other peers.

Second, male nursing students feel succumbed to holding "assertive" and "leadership" responsibilities by their female peers (Anthony, 2004; Dyck et al., 2009, p. 650). As a result, their ability to perform their training in the real-world may be affected (Sedgwick \& Kellett, 2015) as they are expected to not only be high achievers and hold leadership roles, but also acclimate to a feminine learning environment without creating unwanted attention. Meanwhile, male STEM students desire leadership roles compared to female students (Eddy et al., 2015). Although males in nursing may not intend to attain a leadership role, this outcome is different from male STEM students in that they actively pursue this goal. Meanwhile, Dingel (2006) posits that females do not obtain assertive roles to engage in greater "cooperative and collaborative approaches to learning" including their roles in group opportunities (p. 173). As such, females in STEM are less likely to take on leadership roles as their male peers to maintain 
the status quo. Females may also perceive their leadership status as not intended to project "an individual sense of authority" as reflected by their male peers (Dingel, 2006, p. 171).

Third, both male and female STEM students acknowledged "an equal value" in group collaboration, females showed a higher value for teamwork when they had a friend (Eddy et al., 2015, p. 14:ar45, 13). Interestingly, this was not apparent for males (Eddy et al., 2015). Their minority status may negatively catapult them to be in the spotlight for projects that involve a student leader, while female STEM students are projected as they attempt to show representation in classroom leadership roles.

When male nursing students engaged in classroom discussions, several students expressed feeling like "token voices," or asked to participate by faculty to demonstrate diversity in the classroom environment (Stott, 2004; Dyck et al., 2009; Hodges et al., 2017, p. 276). Conversely, female STEM students also experience tokenism, and it influenced their strategy to communicate specific goals. For example, Dingel (2006) found they will be less demanding and have less "inner-strength" than their male peers in overcoming educational adversities (Kanter, 1977; Seymour \& Hewitt, 1997, 162). This, in turn, hinders their ability to be fully integrated into the team settings as they are asked to participate to demonstrate a point or attempt to gather diverse thought. As Sedgwick and Kellett (2015) posited the causes of teamwork challenges, "men's efficacy as nurses may be undermined by the tension between adherence to hegemonic constructions of masculinity that emphasize independence and autonomy and engagement in collaborative social interaction" (Connell, 1995; Evans \& Frank, 2003; p. 126).

Fourth, male nursing students may seek to be more independent, including a lack of desire to collaborate with their peers (Sedgwick \& Kellett, 2015). However, female STEM students are more likely to desire help to achieve affirmation in their abilities (Dingel, 2006). Dingel (2006) added females in STEM also experience similar challenges conforming to a maledominated environment, "by expecting women and men to conform to traditionally masculine or feminine behaviors, such as recognizing men but not women as leaders, these students reinforce the notion that science is a masculine pursuit" due to gender stereotypes (p. 173). In a group work assignment, students who recognize their benefit in their learning outcomes and future careers will show a greater desire to be involved (Oliver, 1974; Eddy et al., 2015). In programs where male or female students do not feel integrated or appreciated for the efforts, their involvement is also impacted, including in teamwork activities. 
In STEM, females are often given easy activities and feel pressure to work harder. They are also less likely to be active participants in classroom activities, including discussions or hold a leadership position in teamwork (Eddy \& Brownell, 2016). While male nursing students have greater pressure to be a leader in teamwork activities and also have more opportunities for leadership roles in professional settings, despite this, male nursing students' proactive engagement in teamwork also translates to overall classroom discussions. Eddy and Brownell (2016) stated "men felt more comfortable answering instructor questions in front of the whole class and were more likely to prefer to take on the role of a leader in small group work compared to women" in either activity (Eddy \& Brownell, 2016, p. 020106-5). The next section focuses on how student interactions in the classroom environment are unique in both respected programs.

\section{Overall Social Environment}

Long (2011) stated it would not be surprising that male public relations students would experience loneliness in the classroom environment, as it occurs in the workplace. It is also known to affect male retention, as they are less likely to pursue the program or drop out before graduation due to their minority status (Long, 2011). The examination of the overall social learning environment aims to explore if public relations students experience social challenges in the classroom, including discussions and other activities that involve the entire class's involvement. The classroom social environment is defined as "a course, encompassing teacher and student behaviors, interactions (teacher-student and student-student), and student expectations of the environment" (Beer \& Darkenwald, 1989; Darkenwald \& Gavin, 1987; KingSpezzo, 2017, p. 9). In experiences related to the classroom social climate, male nursing and female STEM students shared three similar themes addressing class discussion contributions, male humor, and male dissent. Accordingly, this section will take into account interactions working with both faculty and students in classroom discussions and other relevant experiences that may influence public relations students' educational outcomes.

First, the minority status of male nursing students influenced their contributions to classroom discussions and other social exchanges with their instructors and female peers. They are more motivated to contribute and lead classroom conversations by their instructor than their female peers (Fister, 1999; LaRocco, 2007; MacWilliams et al., 2013). STEM males are also more likely to participate in class discussions because their instructors also ask them to do so 
more than their female counterparts (Altermatt, Jovanovic, \& Perry, 1998; Burns \& Myhill, 2004; Eddy \& Brownell, 2016). Nevertheless, in classrooms where females constitute the majority, they continue to contribute less, which may be caused by a lack of "comfort" to be involved (Eddy et al., 2015; Eddy \& Brownell, 2016, p. 020106-3). Fencl \& Scheel (2006) posit that female students "cited reasons such as not having formulated their ideas well enough, not knowing enough about the subject, and not wanting to appear unintelligent than did men, while men were more likely to cite not having done the reading" as additional causes (Crawford \& MacLeod, 1990, p. 288).

As female students are assigned fewer challenging roles (i.e., group activities), they may also be less receptive to class discussions (Seron et al., 2018). Considering these findings, male nursing students may not voluntarily wish to contribute to class discussions as a minority. Yet, even in cases where women constitute both a minority and majority of the class, they are still less likely to participate. Female students face pressure to achieve high academic performance and are less likely to state an answer or add to the discussion that may be incorrect. As such, their "confiden[ce]" in contributing to course discussions is impacted (Rocca, 2010; Eddy \& Brownell, 2016, p. 020106-6).

Second, Dyck et al. (2009) study found that male nursing students engaged in classroom discussions by asking questions and providing insight as well as actively made jokes or entertained during lectures. Although this may be an attempt to diversify student input, this is another obstacle for males as they represent a token voice in discussions. Male STEM students also used humor in the classroom. However, it incorporated the sexist and stereotypical humor of females (Kanack, 2011). These jokes would include stereotypes about females' role as a caregiver or the attractiveness of a female in the program (Kanack, 2011). Female STEM students preferred female humor over male sexist humor (Moore, Griffiths, \& Payne, 1987, p. 5230; Kanack, 2011). In these cases, female STEM students would either take part in the humor to assimilate, also known as "social coping" (Kanack, 2011, p. 48). Although humor can help unify groups, it can also result in "ridicule [for] group members who deviate from norms, and thus reinforce desired behaviors" in the classroom (Lynch, 2002; Kanack, 2011, p.11).

Third, male nursing students were more likely to engage in dissent by questioning their instructor's authority on topics (Dyck et al., 2009). As males perceive their instructors to assimilate them to a feminine environment and identity, they are likely to engage in "risky" 
behaviors to express these challenges (Meadus \& Twomey, 2011; Dyck et al., 2009, p. 651). As a result, Sedgwick \& Kellett (2017) posit that "the learning environment seem[s] to favor feminine student learning and communication styles, some accounts suggest that faculty and female nursing students appear to have entrenched attitudes that may perpetuate gender bias and discrimination toward male nursing students" as causation (Bartfay et al., 2010; Dyck et al., 2009; p. 122).

The overall social environment dimension will be used to determine if the gender imbalance impacts public relations students as well as if there are similarities or differences in student contributions, humor, and instructional dissent between nursing and STEM literature. These social experiences are important to explore, as they can lead to instructional dissent, and the pressure to answer correctly or not to participate at all, and use humor as male nursing students are token voices used to diversify the classroom.

\section{Theoretical Perspective}

This study employed role congruity theory and tokenism, which were informed by the literature (addressed above) and emerging themes from the data. The uses of these theories are two-fold. First, single-gender dominant programs, including nursing and STEM, have used tokenism in addressing social issues for minority group members (Stott, 2004; Dingel, 2006; Dyck et al., 2009; Hodges et al., 2017). Second, role congruity theory addresses leadership that occurs in nurse and STEM teamwork activities. Currently, there are no direct uses of tokenism or role congruity theory to explore the gendered challenges of the social integration of undergraduate public relations students.

Tokenism posits that in a single-gender dominant field, minority group members may feel less included or used in an attempt to showcase diversity. For example, males in nursing programs are often asked by the instructor to participate in class, in order to vary the discussion,

yet also demonstrate their minority status in this action (Stott, 2004; Dyck et al., 2009; Hodges et al., 2017). Female STEM students also experience tokenism, and it influenced their strategy to communicate specific goals. Dingel (2006) found they will be less demanding and have less "inner-strength" than their male peers in overcoming educational adversities (Kanter, 1977; Seymour \& Hewitt, 1997, 162). Accordingly, tokenism will be used to explore if the female- 
dominant classroom causes challenges for male and female students in a public relations program.

Tokenism posits that for group members of gender, race, religion, as examples that represent "lower than $15 \%$ (tokens) provide organizations with the appearance of addressing equality and equity issues but result in interactive dynamics that create barriers to the work and advancement of tokens within the organization (Kanter, 1977a)" (Kanter, 1977; Hirshfield, 2015; $\mathrm{Hu}, 2019$, p. 18). Consequently, those who are in this minority experience challenges, including standing out as a minority, which makes status their become more prominent or adhere to conventional messages of their identity (Kanter, 1977; Hirshfield, 2015).

There are three challenges presented for minority groups experiencing tokenism. First, "performance pressure" is when minority members stand out, causing them to attempt to tone down their status, achievements, or their peers questioning their competence in the academic setting (Kanter, 1977; Dingel, 2006, p. 163; Hirshfield, 2015, p. 2058; Hu, 2019). They may also be more cautious about their achievements to deter recognition (Kanter, 1977; Hu, 2019). For example, if a male public relations student performs higher on an exam, he may receive greater acknowledgments than his female peers. Second, they may encounter "boundary heightening" where minority groups may be excluded from activities by highlighting their distinct attributes by their peers (Kanter, 1977; Hirshfield, 2015, p. 2058). This may result in the internalized judgment of their identity by recognizing it as adversity or rejecting it altogether(Kanter, 1977; $\mathrm{Hu}, 2019)$. A female STEM student may feel less integrated with an activity involving a subject that males may have more interest or knowledge in, as an example. Third, tokens may adhere to conventional perceptions of their identity, also known as "role entrapment" (Kanter, 1977; Hirshfield, 2015, p. 2058). This may cause them to engage in behaviors that are "stereotypical" as they attempt to blend in to the community to achieve effective relationships (Kanter, 1977; $\mathrm{Hu}, 2019$, p. 19). A male nurse may focus on leading a team by deciding member's roles to keep his masculine qualities.

This theory is also notable for its benefits and disadvantages. Tokenism is intended to explore professional challenges but is applies to other settings, including college (Sax, 1996). It has also been endorsed by scholars, as it has been used in studies for decades, adding to its conceptual validity (Yoder, 1991; Hirshfield, 2015). However, much of the research on tokenistic voices focus on females, leaving research on males (including nurses) with a weaker 
foundation (Yoder, 1991; Hirshfield, 2015). Additionally, Hirshfield (2015) pointed out that "theories of tokenism are not always transferable from one setting or group to another. More importantly, the numeric proportion does not account for all of the issues that tokens experience" (p. 2058). Thus, in situations where tokens identify with one or more identities, their challenges may be less measurable. Hu (2019) also noted how males and females experience tokenism may not be equal. Studies incorporating tokenism for specific genders may be difficult to measure. As this study focuses on incoming public relations professionals, the study findings could yield predictive measures of gender minority status in the field. As other studies before, this study addresses if in a female-dominant environment, if male, female, or both experience tokenistic social challenges in the classroom environment (Sax, 1996).

Role congruity theory will also be used, as it reflects leadership in teamwork activities. Studies that employ this theory are concentrated in industry and address that female workers encounter adversities in attaining leadership positions in the workplace. These challenges are caused by hegemonic views of masculine and feminine behaviors as they apply to leadership qualities and promotion:

"Men, more than women, are concentrated in roles that emphasize power, competition, or authority. At the same time, women traditionally have easily entered roles that are considered suitable to feminine stereotypes (e.g., in education), such as those that involve caring or giving support, or that put emphasis on human interactions (Eagly, 1987; Eagly, Wood, \& Diekman, 2000; Garcia-Retamero, 2006; López-Sáez, 1994; López-Zafra, 1999). Hence, the characteristics associated with leadership roles have been attached more to men than to women" (Garcia-Retamero \& Lopez-Safra, 2006, p. 51).

Role congruity theory been shown in male nursing students who often obtain "leadership" roles as encouraged by their female peers (Anthony, 2004; Dyck et al., 2009, p. 650 ). Females in STEM programs are less likely to be a leader in male-dominated group work activities (Dingel, 2006; Eddy et al., 2015).

Role congruity theory posits several social challenges for female leadership. Eagly and Karau (2002) stated two possible disadvantages for females affected by role congruity, including "possessing less leadership ability than men" or given a "less favorable evaluation of behavior that fulfills the prescriptions of a leader role" from the assessment of a male (p. 588). Females who transition to a leadership role, may their feminine traits to be perceived as misaligned with 
leadership resulting in a lack of female presence (“descriptive bias) or go against traditional hegemonic roles by showing masculine traits ("prescriptive bias") which lead her to being judged poorly (Johnson, Murphy, Zewdie, \& Reichard, 2008, p. 40).

In a female-dominated industry, role congruity theory showed that females were perceived to be more likely to receive a promotion (Garcia-Retamero \& Lopez-Safra, 2006). In male-dominated fields, this is not the case, as "incongruity would be greater in male-congenial organizations" (Eagly \& Karau 2002; Garcia-Retamero \& Lopez-Safra, 2006, p. 52).

There are several noted challenges in approaching role congruity. First, this study focuses on students who are likely to enter the workforce following graduation, yet, the use of theory is often applied to professional and workplace settings (Eagly \& Karau, 2002; Garcia-Retamero \& Lopez-Safra, 2006). Additionally, it is almost exclusive to female challenges in the workplace (Ely, 1994, 1995; Eagly \& Karau, 2002; Garcia-Retamero \& Lopez-Safra, 2006). This theory is most appropriate in addressing the professional challenges experienced in the public relations industry. This lens can provide insight into challenges experienced with caution that environments that are female-dominant can affect the fit of the theoretical lens. One common challenge addressed by public relations professionals is the lack of female leadership (Long, 2011; Krugler, 2017; Place \& Vardeman-Winter, 2018), this study addresses leadership in teamwork activities, and this lens can understand the power dynamics within the classroom environment.

\section{Current Study}

In summary, there are three decades worth of literature that has examined the social challenges caused by the gender imbalance (Toth, Aldoory, \& Sha, 2006; Geyer-Semple, 2012; Vardeman-Winter \& Place, 2017). As the gender composition within the public relations field and programs are similar (Gotlieb et al., 2017; BLS, 2019), it may also be consequential to students. Two recent studies inferred this, such as exclusion from activities and lowered positive outcomes in the course for male students (Waymer et al., 2018; Brown et al., 2019).

There are other programs are female-dominant (nursing) and male-dominant (STEM) that encounter similar adversities experienced by public relations professionals. Namely, gender discrimination (Long, 2011; Rajaich et al., 2013; Carter et al., 2019) and stereotypes (Peters \& Froelich, 2006; Rajaich et al., 2013; Carter et al., 2019). Studies have also informed that the 
gender imbalance within the field and class settings can be consequential for social environments as they impact attrition rates and later set the tone for the professional environment (Levett-Jones et al., 2007). Literature from nursing and STEM education has shown three dimensions in which social challenges can occur. First, role strain which involves identity management and can affect gender stereotyping and academic performance (Dingel, 2006; Dyck et al., 2009; Eddy \& Brownell, 2016). Second, teamwork involving student-to-student interactions, can impact leadership, independent, and dependent behaviors (Dingel, 2006; Dyck et al., 2009; Sedgwick \& Kellett, 2015). Third, the overall social environment encompasses interactions involving student participation in class discussions (King-Sprezzo, 2017) and can influence the use of humor and instructional dissent (Dyck et al., 2009; Kanack, 2011).

The two theories posited are informed by the literature (addressed above) and the data findings. Tokenism addresses how minority group representation can create the perception of inclusivity, yet lead to externalities (Kanter, 1977; Hirshfield, 2015; Hu, 2019). For example, students becoming cautious about their successes, excluded from activities, and adhering to conventional messages as a minority (Kanter, 1977; Dingel, 2006, p. 163; Hirshfield, 2015, Hu, 2019). Role congruity theory addresses how traditional roles of masculine and feminine behaviors can exclude females from leadership opportunities (Garcia-Retamero \& Lopez-Safra, 2006). It can result in a lack of female representation in leadership or females engaging in masculine behaviors, which can result in her being judged poorly (Johnson, Murphy, Zewdie, \& Reichard, 2008).

As the exploration of what types of student social challenges that occur in the public relations classroom is relatively new, this study will involve the emergence of theory derived from the data findings.

Using the qualitative methodology, grounded theory, this study examined the following research questions:

RQ 1: How does gender majority status impact females social learning outcomes in the upper-level public relations classroom?

RQ 2: How does having gender minority status impacts male public relations students' social learning outcomes in the upper-level public relations classroom?

RQ 3: How is this similar to or different from other single-gender dominant programs? 


\section{CHAPTER 3 \\ METHODOLOGY}

\section{Use of Grounded Theory}

This study seeks to answer how the gender imbalance impacts upper-level public relations students, and what similarities or differences exist with other single-gender dominant programs such as nursing and STEM. This study employed the qualitative method grounded theory because, the subject is relatively new. Grounded theory "is the systematic generation of theory from systematic research. It is a set of rigorous research procedures leading to the emergence of conceptual categories" (Grounded Theory Institute, 2013; Cho \& Lee, 2014, p. 2). This framework used a systematic approach (Strauss \& Corbin, 1994; Corbin \& Strauss, 2007) and followed the processes recommended under the Straussian school (Jones \& Alony, 2011):

1. The researcher has a general idea of where to begin.

2. The researcher uses structured questions to force theory to emerge.

3. Identifying variables and relationships are derived from the methods.

4. The researcher interprets the data.

5. The theory is derived from the rigor of the method.

6. The researcher is an active part of the data process.

7. The data is structured to emerge the theory.

8. The coding process is defined (e.g., codes are carefully crafted) and rigorous.

9. The researcher uses open, axial, and selective coding in the data analysis process.

This study used semi-structured interviews. The questions asked were open-ended because it is a part of the grounded theory procedures and ensured that participants were able to explain their responses to the questions freely, to gather a well-rounded understanding of the phenomena (Groat \& Wang, 2002; Cho \& Lee, 2014).

\section{Researcher Bias}

The disclosure of the researcher's bias is necessary because "the researcher is the data collection instrument and cannot separate themselves from the research" in the data collection and findings processes (Jackson, 1990; Fusch \& Ness, 2015, p. 1411). In order to ensure accuracy, the 
researcher will disclose any pertinent information that may impact the study findings in an attempt to provide the most accurate description of the phenomena that occurred.

The researcher is a female who holds a bachelor's degree in strategic communication with an emphasis in public relations and identifies as both Caucasian and Hispanic. The researcher shares characteristics as a female student with field interest in public relations. For female participants, this may have affected their comfortability in answering the interview prompts. The researcher was not currently enrolled in a 300- or 400- level strategic communication or public relations course at the time of data collection and did not recruit students as their peer in the classroom. All of the findings were derived from the participants' direct responses to provide an accurate analysis (Hollaway, Brown, \& Shipway, 2010).

\section{Data Collection}

Upon approval from the Institutional Review Board (IRB) protocol number: 1911782791, the participants read and signed (or electronically signed) the study consent form (see APPENDIX B) before to the interview process. The participants' location preferences were a priority, as the interview site may determine their level of comfortability in discussing their experiences (McGrath, Palmgren, \& Liljedahl, 2019). The majority of the participants (three males, six females, and one gender non-conforming female-presenting) opted for a phone call interview. The remaining in-person interviews took place where the researcher worked (which was located inside of the college) in her office or an open room within the college building. After the researcher read the study outline and purpose, the participants were asked for permission to record their interviews. All participants agreed, and the interviews were recorded using a Zoom H1 Handy Recorder device provided by the college.

The researcher's procedures and questions were read from the qualitative prompt, and participants were probed on their responses to explore their experiences and how it influenced their learning outcomes. This study explored how gender imbalance can impact upper-level public relations students, and what similarities or differences exist between nurse and STEM programs. The interview protocol format was inspired by Krugler (2017) and aimed to cover three dimensions (i.e., role strain, teamwork, and overall social environment). The first set of questions addressed how the participants' social interactions influenced their work ethic and academic determination. These prompts included their academic expectations in comparison to 
their male and female peers, instructor praise, and whom they would contact for help in their class (i.e., a classmate or the instructor). The second set of questions asked about their experiences working in teams, including interactions with their peers. The prompts included their role in the group, similarities or differences in working with their male and female peers, benefits and disadvantages working in the group, and group challenges. The third set of questions discussed interactions involving the entire classes' voluntary and involuntary participation, class discussions, and any other overall class activities. These questions included easy or difficult experiences, if they felt they were treated differently, and their perception of the environment working with male and female peers (see APPENDIX A).

Following the in-depth interview process, the participants were asked to complete an online Qualtrics survey, in which their demographic information was collected. There were no further studies conducted following the initial data collection process. After all, in-depth interviews were completed, the audio recordings were sent to Rev.com to be transcribed. The researcher re-read and listened to the transcribed documents to ensure accuracy. Following this, all recordings of the participant interviews were permanently destroyed (as outlined in the IRB protocol). All transcriptions were securely located under a password locked computer that was stored in a secure area.

\section{Coding Process}

After re-reading the transcripts for accuracy, the researcher created individual documents for each interview prompt question. Each document was highlighted to indicate that the section had not been categorized into its respected response document. The researcher denoted the response had been categorized once the section was not highlighted. This process was completed once all documents had no remaining highlighted areas.

The researcher began the grounded theory data analysis process which, included open coding, axial coding, and selective coding. The researcher followed the analysis steps employed by Cho and Lee (2014), which were also under the Straussian method (as described above). First, the researcher began the open coding process that highlighted to denote a section that was not coded and gave corresponding codes using sentence in-vivo coding, which is derived from the participants' actual words. Manning (2017) stated in-vivo coding would aid to "understand stories or ideas through the actual words of participants, and it has also been noted for its ability 
to help offer a sense of nuanced meaning that other forms of coding" restrict from the findings (p. 1-2). This process was complete once all of the participant responses were no longer highlighted in each question response document. All codes for the corresponding questions were highlighted and featured the participant number to track each statement. The statements that were found to create an emerging theme where placed on the table, listed with the theme title, and denoted as used under the participants' codes by un-highlighting the response. This process was completed until there were no remaining highlighted responses.

The researcher began the axial coding process by creating new documents featuring a table for the coded responses. The researcher looked at frequent themes to determine patterns between each dimension for the main themes to emerge. All themes that were considered under this criterion were moved to a new document that featured all other significant findings from each dimension (i.e., role strain, teamwork, and overall social), and denoted where the theme emerged.

In the selective coding process, the researcher reviewed all of the significant findings and looked for patterns in the themes (e.g., between teamwork and overall social environment) to determine the main themes. The themes that were selected were determined if they were both frequent and featured a minimum of four participant direct quotes mentioning the phenomena and reached saturation from the data collected (Cho \& Lee, 2014). After determining the main themes, the corresponding participant number, and question were traced back to find the direct quote in which the participant addressed the theme to validate its occurrence in the data findings.

\section{Sample Characteristics}

The sample consisted of 3 males, 9 females, and 1 participant identified as gender nonconforming and female-presenting. The participants' ages were between 20 and 22 years old, undergraduate students with a junior- or senior- academic standing currently attending a large, mid-Atlantic university. According to the Assistant Dean for Student and Enrollment Services, the program major has a 16:61 male to female ratio. Acronyms supplement the participant direct quotes for their gender and race identities $(\mathrm{M}=$ Male; $\mathrm{F}=$ Female; $\mathrm{GNC}=$ Gender NonConforming; $\mathrm{C}=$ Caucasian; $\mathrm{A}=\mathrm{Asian}$ or Asian Indian; $\mathrm{AA}=\mathrm{African}$ American) (see Table 1). The study sought to have an equal amount of male and female participants (12 each), and the male response rate was considerably low. Despite this, the data collected was significant enough 
to reach saturation (Creswell, 2013) to complete the collection process. Subsequent studies are recommended to recruit more male participants to gather a well-rounded understanding of the phenomena. 
Table 1. Participant Demographics

\begin{tabular}{|c|c|c|c|c|}
\hline Participant & Gender & Academic Standing & Age & Race \\
\hline 1 & Female & Senior & 21 & $\begin{array}{l}\text { Caucasian, Asian } \\
\text { or Asian Indian, } \\
\text { and African } \\
\text { American }\end{array}$ \\
\hline 2 & Female & Senior & 21 & Caucasian \\
\hline 3 & Female & Junior & 21 & Caucasian \\
\hline 4 & Female & Senior & 21 & $\begin{array}{l}\text { African } \\
\text { American }\end{array}$ \\
\hline 5 & Female & Senior & 21 & Caucasian \\
\hline 6 & Female & Senior & 22 & Caucasian \\
\hline 7 & Female & Junior & 21 & Caucasian \\
\hline 8 & Female & Junior & 20 & Caucasian \\
\hline 9 & Female & Senior & 22 & Caucasian \\
\hline 10 & $\begin{array}{l}\text { Gender } \\
\text { nonconforming } \\
\text { (female- } \\
\text { presenting) }\end{array}$ & Senior & 21 & $\begin{array}{l}\text { African } \\
\text { American }\end{array}$ \\
\hline 11 & Male & Junior & 21 & Caucasian \\
\hline 12 & Male & Senior & 22 & Caucasian \\
\hline 13 & Male & Senior & 22 & Caucasian \\
\hline
\end{tabular}




\section{CHAPTER 4 \\ FINDINGS}

This study examined whether the gender imbalance impacts upper-level public relations students, and what similarities or differences exist between other single-gender dominant programs such as nursing and STEM. The study yielded 20 initial themes, which were reduced to six (6) main themes comprising of 59 open codes (see APPENDIX D). The study found emerging themes including female-to-female reliance, female-to-female competitiveness, female leadership, perceived low male work ethic, male humor, and siblings and comfort in opposite-sex interactions (see Table 2).

\section{Table 2. Themes}

Theme

Description

Codes

\begin{tabular}{|c|c|c|}
\hline Female-to-Female Reliance & $\begin{array}{l}\text { Discusses how females form } \\
\text { relationships from a perceived } \\
\text { greater understanding, } \\
\text { productive working } \\
\text { relationship, shared } \\
\text { communication styles, and a } \\
\text { general reliance from students } \\
\text { of the same gender }\end{array}$ & $\begin{array}{l}\text { 1.1. F-F Understanding } \\
\text { 1.2. F-F Comfort } \\
\text { 1.3. F-F Communication } \\
\text { 1.4. Organic gender } \\
\text { segregation }\end{array}$ \\
\hline $\begin{array}{l}\text { Female-to-Female } \\
\text { Competitiveness }\end{array}$ & $\begin{array}{l}\text { Discusses why females feel } \\
\text { the need to compete with } \\
\text { other females in academic and } \\
\text { career opportunities, and less } \\
\text { desire to compete with male } \\
\text { peers }\end{array}$ & $\begin{array}{l}\text { 2.1. Female-to-female } \\
\text { competition } \\
\text { 2.2. Females-to-female } \\
\text { comparison } \\
\text { 2.3. Desire to stand out from } \\
\text { other females as a female } \\
\text { 2.4. Do not compete with } \\
\text { male peers }\end{array}$ \\
\hline
\end{tabular}




\begin{tabular}{|c|c|c|}
\hline Female Leadership & $\begin{array}{l}\text { Discusses why female } \\
\text { students held more leadership } \\
\text { roles than males, a lack of } \\
\text { male interest in leadership, } \\
\text { and same-sex gender } \\
\text { receptiveness in group work } \\
\text { activities }\end{array}$ & $\begin{array}{l}\text { 3.1. Females were leaders in } \\
\text { teamwork } \\
\text { 3.2. Males were not interested } \\
\text { in leadership roles } \\
\text { 3.3. Gendered communication } \\
\text { receptiveness }\end{array}$ \\
\hline $\begin{array}{l}\text { Perceived Low Male Work } \\
\text { Ethic }\end{array}$ & $\begin{array}{l}\text { Discusses how males } \\
\text { experience academic } \\
\text { challenges including } \\
\text { a lack of effort, contributions } \\
\text { to activities, and a lack of } \\
\text { male presence in the } \\
\text { classroom environment }\end{array}$ & $\begin{array}{l}\text { 4.1. Contribute less in group } \\
\text { discussions } \\
\text { 4.2. Reminded to complete } \\
\text { coursework } \\
\text { 4.3. Put in less effort than } \\
\text { females } \\
\text { 4.4. Lack of experience } \\
\text { working with males }\end{array}$ \\
\hline Male Humor & $\begin{array}{l}\text { Discusses how males use } \\
\text { humor in the classroom } \\
\text { including class contexts, } \\
\text { purposes, and reactions to } \\
\text { male humor }\end{array}$ & $\begin{array}{l}\text { 5.1. Males try to entertain the } \\
\text { classroom } \\
\text { 5.2. Males use classroom } \\
\text { contexts for humor } \\
\text { 5.3. Male jokes are received } \\
\text { negatively by females }\end{array}$ \\
\hline $\begin{array}{l}\text { Siblings \& Comfort with the } \\
\text { Opposite Sex }\end{array}$ & $\begin{array}{l}\text { Discusses how male and } \\
\text { female public relations } \\
\text { students with opposite-sex } \\
\text { siblings have greater comfort } \\
\text { and relatability to their } \\
\text { opposite-sex peers }\end{array}$ & $\begin{array}{l}\text { 6.1. Sibling of opposite sex } \\
\text { 6.2. Level of comfort with } \\
\text { opposite sex }\end{array}$ \\
\hline
\end{tabular}




\section{Female-to-Female Reliance}

All-female participants stated that when they needed to ask a peer for help, they would rely on another female in the classroom. The overall theme found that female participants rely on each other because they felt other females understand them, are more comfortable, and felt communication was easier. This same-gender reliance may be to develop relationships with their classmates, to ask questions about assignments, or to collaborate in team activities.

Participants described how they felt more understood by other females, including their mindset, emotional nature, and shared interests as described in their own words:

Participant 1 (F, C, A, AA): "I feel like the things I'm saying, they [females] probably relate to me more and understanding what I'm saying instead of like having a differently mindset listen to something that I'm saying. They're probably not going to agree or understand what I'm even trying to say."

One participant felt her female peers understood her emotional nature:

Participant 3 (F, C): "Just because they [females] understand how emotional I can be with assignments. All my friends. And I feel like they understand better and since they are in the same class as me, they can help me better than someone that's not in the class."

Two participants addressed that they held shared interests with their female peers:

Participant 5 (F, C): "I felt like I could relate to them [females] more. I just made more sense to them."

Participant 6 (F, C): "I feel like girls definitely fall into more conversations about mutual things that they have in common already and build off that and build their relationships off that too. We could be strangers but I could say like, "Oh I love your sweater." And we end up having a 15-minute conversation about clothes and then the next day we're working better together because we had that bonding. Not even just like it's about materialistic things, but anything, whether it's about TV shows we like or stuff like that, I feel like girls just gravitate towards each other, to be that more open and friendly conversation."

Participant 9 (F, C): "I'm closer with my female peers, and I feel like they might have a better understanding of what I'm going through than my male peers."

Participants discussed that they felt more comfortable around classmates of the same sex because it is easier to develop friendships and work with one another. 
Participant 4 (F, AA) stated: “That's just because at this point they're the ones I've built a friendship with rather than the men. I just haven't really tried, especially because girls are just easier to talk to." Participant 7 (F, C) added: "I don't dislike working with males. I just feel like it's easier to talk to females and just ... I don't know, it's just more comfortable I guess working with another girl rather than working with a guy."

The female dominant environment may also play a role in female comfortability.

Participant 5 (F, C) stated: "I feel, for me, it was comforting just because I saw so many females and being a female just made me feel just more comfortable being there." Similarly, Participant 9 (F, C) said: "I think I would be more comfortable reaching out to a female peer only because I think that I'm closer with my female peers." Participant 10 (GNC, AA) added: "So I found out she was going to be doing that [letting students chose their teams] and I decided to be in her group because I felt comfortable with her. So, I feel like that's a good dynamic."

Participants discussed how being in a female-dominant environment makes it easier to have conversations with females, including to ask questions because of the comfortability and female bond.

Participant 6 (F, C) said: "Female[s], definitely to ask questions, just because again, I think it's like, not that I don't feel like I could ask the males, but I feel like girls have that unspoken bond of just the approach of asking the question. I definitely just feel more comfortable asking a girlfriend, being like, "Hey, could you help me with this?" Participant 7 (F, C) stated: "I think girls are just easier to talk to. I don't really want to use the word intimidating, but I just feel like girls are just easier to talk to I guess is what I would say."

Two participants also discussed their level of comfortability working with other females.

Participant 4 (F, AA) stated: "with class discussions, it's just easier talking to the women. But if we're doing a chapter where a guy's leading, then I feel comfortable asking him about the assignment since he's in charge." Participant 5 (F, C) stated: "I'm a quiet and shy person and since I am a female, I feel like it's easier for me to ask the females questions or be like, "Hey, can you help me with this?", whereas if it's a male I'm not really close with, I feel like I'm going to be a little more intimidated to be, "Hey, do you want to help me figuring out how to do this?" So, I feel like I tend to go more towards the females." Participants also discussed an organic gender segregation in that females rely on other females 
and males rely on other males for their opinions and help in the classroom:

Participant 3 (F, C) said: "I feel like females stay with females and males stay with males, unless you have best friends in the class and then maybe you'll split off a little bit. But other than that, yeah, I feel like we all stick to our genders."

Participant 4 (F, AA): "I feel like women are more comfortable in classes that are filled with more women."

Participant 6 (F, C): "I definitely feel like females tend to ask more females their opinions and questions and males tend to stick with males."

Participant 7 (F, C) explained: "Just for the same reason, I'm sure that they probably think it's easier to talk to another guy than it is to reach out to a girl. Just based on how people are in classrooms, usually guys sit with other guys, girls with other girls. So, it's just kind of instinctual. I guess for females to reach out to just to ask another female or male for male."

\section{Female-to-Female Competitiveness}

Another theme is female-to-female competitiveness in which participants discussed that they felt they had to compete with other females in the classroom, compared themselves to other females, desired to stand out among their female peers, and did not feel they competed with their male peers. Participants stated they felt competitiveness in that they share the same amount of skills and knowledge. As their statements reflected:

Participant 3 (F, C): "I just feel like there's so many females in my classes, other than males, and they're all really smart and nice, and I feel like they'll go to big places someday and I just feel like sometimes I lack some things that they do."

Participant 6 (F, C): "I mean obviously it is mostly females, so I definitely, when you see someone sitting next to you, like your friend that you were just joking around with and they're answering these questions and have all their stuff done and sometimes I get nervous, maybe I'm not on the same page as them. Why do they seem like they know more?"

Participant 9 (F, C): "I think that with the females that I've been in class with and that I'm going to be graduating with, I feel as though we're more similar on those fronts [strong writing and leadership skills] than I am with a male." 
Participant 10 (GNC, AA): "I just feel like there is a lot of understanding and things like that, but the females also pushed me to work harder as someone that's also female." As the participants are in a female-dominant environment, they described that they compare themselves to female students through academic successes or internship opportunities, and the negative consequences associated with this.

Participant 2 (F, C): "With females it's always like who can do better? That's kind of just how I feel."

Participant 4 (F, AA): "I'd say comparing yourself to the other women might be a difficulty. If someone is getting lots of internships or attention on social media because that could really boost you in this field. So I would say envy or something like that might be a difficulty."

Participant 5 (F, C): "I think the most difficult things are trying to make yourself stand out from the rest of the females, and also what they expect. Do I reach those expectations? Because I feel now, since there's so many, you should be a certain way, and then when you're not I feel like it might make it a little bit harder because, just because I'm not submitting work this, or doing things this way, or acting a certain way."

Participant 6 (F, C) noted this comparison may not be beneficial, "Females are really comparing themselves to each other in maybe a negative light more mentally than outspoken, which I think could probably have negative effects in the long run if just female with the, I don't want to say jealousy, but females definitely do have their own competitive factor whether they realize it or not, I feel."

Similarly, in competing with female peers, participants described that they desired to stand out. Specifically, by seeking to do better their female peers academically, obtaining an internship opportunity, or a job related to the program. The participants addressed this finding:

Participant 2 (F, C): "When I'm interacting with females in my group, I feel like there is a kind of... And I try not to have this mindset, but I feel like it's there in a way. Because we're females, it's like, "Oh, you know I can do better than you,' and kind of one-up you." Participant 3 (F, C): "I have friends that are so motivated and do better than me at some projects and then I'm a very competitive person by nature, so I honestly just want to succeed and be better than everyone in my class, which sounds bad, but I just want to do the best that I can do and rise above everyone so I can get that job someday." 
Participant 5 (F, C): "I feel like I do have to work way harder, because when I see other people I'm, 'Okay, they have all this experience, they've worked with this nonprofit, they've done this.' So, I feel like you have to work harder to make yourself stand out. But in the classroom I feel like not as much."

Participant 6 (F, C): "I don't think females necessarily want to be the best, it's just like, 'I want to be better than her. I don't want to be the best as a whole, but now I feel like I have this competitiveness with her so I want to beat her out."

Participant 10 (GNC, AA): "Because there's so many females so you don't want to be a part of the mix, you want to stand out."

Participants addressed that they do not feel as much competition with their male peers as they do their female peers. This is because the environment is female-dominant, females experience envy from females, males encounter academic difficulties, and males compete with other males.

Several participants addressed a lack of desire to compete with males because of the female-dominant environment:

Participant 8 (F, C) stated: "Honestly, just that there are more of us than there are of them. And if we need to team up on them then we definitely could but I've just not really felt threatened by them." Participant 2 (F, C) said: "Males are more supportive just because they realize that they are kind of the only male, or one of the few males, in this major. So it's kind of hard for them to try to be as competitive as kind of the females in a male vocation."

Several participants addressed their competitive nature is specific to females.

Participant 4 (F, AA): said "I think women are generally more envious of each other. Just one of my friends was because some girl was saying how she had a social media internship and my friend was just saying how she wished she could get more job offers."

Participant 9 (F, C) stated: "Whereas, the females that I've had class with are, so that's why I feel like I would be competing for a job more with them than the males. Whereas, the females that I've had class with are, so that's why I feel like I would be competing for a job more with them than the males."

Participant 10 (GNC, AA) stated: "I feel like since they don't really assert themselves very much in the class, that I don't feel that need to compete with them."

One participant addressed female envy. 
Participant 6 (F, C) said: "I'm sure males have the same competitive [nature], probably feel it more compared to other guys. But again, I'm not as jealous of a male student as I am of a female student's mentality and work ethic. Whereas I'm sure guys aren't as jealous of females' work ethic versus the other guy in their class who they feel that they're neck and neck with."

\section{Female Leadership}

This study found that 8 of the thirteen participants mentioned that their team group leader was a female. The overall theme found that males did not desire to hold a leadership position in group work activities and that males' suggestions in discussions were less reciprocated than female suggestions. In addressing female leadership, participants stated that females were more likely to pursue leadership roles:

Participant 1 (F, C, A, AA): "Women are more seen as organized and the motherly type, so a lot of it is group work. So, they're kind of ... we're always appointed as the leaders of the group because they'll know that we'll be able to handle the tasks that are surrounding us and we'll be able to maneuver around our group members and get everyone to work together."

Participant 2 (F, C): "So I will say that I am the leader in the group, based off of my own... Like I said, my personality has very leadership qualities."

Participant 5 (F, C): "I feel like the females tend to take on more of the leader of the group and, 'Okay, you do this part, I'll do this section, we'll meet on these days, we'll do whatever.'

Participant 6 (F, C): "It's the females are more of the leaders. But again, even with a small group, even though there is a leader, I will say that despite gender, everyone works very well together and has respect, overlying respect as a whole."

Participant 10 (GNC, AA): "I was actually the leader. I started to take the leader position because I'm really good at finding people's strengths and weaknesses."

The participants also discussed that males did not desire to have a leadership role in teamwork activities. Two participants discussed that males might not seek a leadership role.

Participant 9 (F, C) said: "Like the male students that I've been around aren't necessarily want to put themselves out there and want to be leaders and stuff. I mean the males 
basically said like, do whatever you want and we'll just do what you tell us to do."

Participant 12 (M, C) stated: “Honestly, no, but I don’t think I wanted to lead. I think probably because I didn't know everything."

Participant 5 (F, C) said: "In any of the groups I worked with, honestly, no."

One participant addressed that he did not want to be viewed negatively if he had a leadership position.

Participant 11 (M, C) stated: "I sometimes don't really want to take the leadership role just cause I don't really want to seem like a bossy kind of guy, or like, a dick." Participants also described that males' contributions in group discussions were less accepted by their female peers. Two participants described a lack of dependence on males. In working under both a male and female leader, Participant 7 (F, C) said: "I think we definitely respond better to the female just because when we have met it just seems like she takes more the reins with things. So far, we've really only heard from the male through GroupMe. And I think communicating in person is much more efficient and effective than through GroupMe because if we're face-to-face it's easier to reiterate what needs to get done, what we need to do." Similarly, Participant 4 (F, AA) stated: "The guy, although he was the lead, I feel like everyone, they didn't really rely on him as much as we did when the girl was the leader, because he just didn't really seem to know exactly what he was doing."

Participants also discussed how females agreed with each other and male input was more disagreed upon within the team.

Participant 6 (F, C) said, "I've definitely seen, working in the library in a group on a latenight project, mostly girls, a guy be like, 'What if we add this?' And all the girls being like, 'No, we already have our creative flow going, you're off track. That's not it.' Kind of shot down type of thing, 'You're thinking too differently than our opinion. What we just agreed to work on, now you're adding in these other ideas that we just don't agree with." Participant 8 (F, C) added: "If I went against something, I won't say their name. If they said something and I went against it, usually everybody else would agree with me."

\section{Perceived Low Male Work Ethic}

Participants discussed how males contribute to the classroom environment, especially in teamwork activities. Notably, the participants addressed that males contributed less, were 
reminded to complete coursework, put in less effort, or a general lack of experience working with males.

In contributions to group work, participants addressed males lack of attention, females contribute the most work, and males are expected to contribute less:

Participant 2 (F, C): "Honestly, I have been in groups in PR classes with guys and they just... you just realize like, 'Hmm, they're not really all there.' Or they weren't paying attention, it's clear like us two girls in this group have to take over, they don't really know what they're talking about it just makes me perceive like they weren't paying attention. They're not into it as much as they should be and it kind of shows that they don't really like they're major a lot."

Participant 7 (F, C): "From what I've experienced, it seems like there are always a few guys that will still voice their opinion or give their thoughts. Then there's always a couple that are just sitting and listening more so than talking, contributing to the conversation. Being in a female dominant class, I think people aren't expecting guys to say as much. They [males] just don't speak out as much in group discussions or offer their opinion as much"

Participant 12 (M, C): "I honestly don't really have a say. I feel like the females were talking more. And I would just listen. I didn't know what to say. It sounds like they had the things in the back, but there were some things I would say no to."

Several participants addressed that males do not try hard in their coursework.

Participant 9 (F, C) stated: "So, I feel as though if you're, especially if it's a group of mostly females, they're probably going to get all of the work done, and then the male's just going to coast along and go along with what the females are doing, and probably get a good grade because without having to put in half the effort or work that the females did." Participant 10 (GNC, AA) said: 'I feel like they don't really have to try very hard. They just are relaxed and they do whatever they need to do to pass the class. Not necessarily saying that they don't try hard to do their work, but they don't seem like they're competitive with anyone else in the class. I don't know that they feel the drive to do better. That's just from my opinion, I don't know for sure."

Participants also discussed the struggles of males involved in primarily group work activities. In particular, they discussed that female students reminded or were left to finish their male team 
members assignments, males desired to pass the class, less willing to complete coursework, and slacked academically. The participants discussed this:

Participant 3 (F, C): “We always had to pick up his slack. He wouldn't do anything and we'd have to be like, hey, this is the deadline. You have to get it by then. We just had to kept hounding him to do stuff. When we could have gotten an A, we got a B, because we had to rush to do his part to turn it in."

Participant 5 (F, C): "I feel like it was always when I was with more males in a group, I had to push them to do more of their work or be more thorough in it. The females I've worked with always tend to be on top of it and give 110\% effort. Based on mainly just the people I have worked with, the girls team just in general care more and wanted a good grade, wanted a good grade in the class, where a lot of the guys were, 'Okay, I have a C, I'm passing, that's good enough for me.', when the rest of the group is, 'Okay, but we want the A so you have to help us get there.', if it was a group effort, so it took everybody." Participant 7 (F, C): "Not to say guys don't do their work, but I just feel like girls are more willing to just do it. Whereas guys you maybe you have to remind them or get them to provide more detail or go back over their work."

One participant in particular, addressed how his work ethic impacted his team. Participant 12 (M, C) said: "I have occasion to slack off to do things to the last minute, which is a bad habit. What I learned from that is that, it's worse if you're holding up other from people doing it."

The participants also discussed how they felt males put in less effort than females in their coursework. This was applicable in contributing the bare minimum in coursework, a lack of effort and motivation. The participants described their experiences:

Participant 7 (F, C) said: "I just feel like guys don't have as much motivation as girls when it comes to classwork I guess." Participant 2 (F, C) stated: "I do feel like some of them are a little bit lazier. So based off of my group, I do notice that... I mean, some of the girls do it as well... It's like there's a consistent procrastination with boys, it's a last-minute thing. So I feel they're not good at time management and they're kind of unorganized." Participant 5 (F, C) said: "They [males] just did what they had to and didn't do much else. Whatever they picked to do or the leader assigned them to do, they would do it, be done with it and not really try to go above and do anything else." 
One participant discussed how she felt female students cared more about their work. Participant 9 (F, C) said: "I feel like the female students in the group care more about what's going on. Not that the male students don't care about their degree and care about their classes, but I feel like female students become more invested in a project. And like I said earlier, they want it to be the best, so they put all their efforts into. Whereas, the males get it done and they do a good job, but it's not something that consumes a lot of their time." Participant $11(\mathrm{M}, \mathrm{C})$ stated: "I am in a group with only female students. I must take the backseat like I said and just do my part and help them."

Participants discussed that in the female-dominant environment, they had a lack of experience working with male students. They noted a lack of male presence. Participant 3 (F, C) said: 'I haven't had a predominantly male class, there's been a lot more females than males in all my classes." Participant 13 (M, C) stated: "I’ve worked with more females."

In a female-dominant environment, participants addressed how this impacted their or their male peer's experiences.

Participant 1 (F, C, A, AA) stated: "I think in my one PR class there was one or two guys. So I feel if anything they' probably feel more out of a place than I do.” Participant 11 (M,

C) said: "I just think there aren't that many males in the PR classrooms I have and then in out of the males I interact with, that I just don't think there are any I personally identify with as friends."

Participant 7 (F, C) stated: "I haven't had a ton of experience working with guys, but it's mostly girls and there are a few guys and it seems like the girls are more of the ones that are taking lead and getting things going and the guys are just not in the background, but they keep to themselves more."

\section{Male Humor}

Participants discussed how males use humor in the classroom environment. The findings showed that the use of male humor might occur in an attempt to entertain the class, use in-class contexts for humor, and was not found to be received positively by female participants.

In entertaining their peers, participants discussed how males would make jokes, including commentary which, were intended to entertain the classroom or warrant attention. The participants explained this occurrence: 
Participant 6 (F, C) said: “I wouldn’t even say jokes, as in full blown ha, ha, knock, knock jokes, but just commentary to lighten the mood. Little comments that are just like, 'Okay, well sure. But you didn't really have to make that comment.' More or less."

Several participants posited why males use humor in the classroom.

Participant 7 (F, C) stated: "I think males just want to present themselves as funny and charismatic. I feel like that's just the thing men pride themselves in is being funny and being able to make other people laugh, especially females. So to see a male and a female dominant class, getting a bunch of females to laugh." Participant 4 said: "Making jokes and laughing really loudly. I think they just egg each other on, like men do. Maybe [to seek] attention."

Participant 12 (M, C) stated: "I am somebody that has a sense of humor who is not afraid to speak my mind. And I could actually be kind of funny at times. You could ask classmates I've had that sometimes they'd enjoyed to be in a classroom with because I actually could entertain the class with my sense humor."

Participants discussed when the use of male humor occurs in the classroom environment. To which depends on the classroom activity, context, or use of spontaneous humor. The participants illustrated this experience:

Participant 12 (M, C) said: "Telling jokes that either fit the spot or jokes that just came out of nowhere."

Participant 6 (F, C) stated: "Little shout outs here and there if we're watching a video, 'What is that girl doing in the video?'

In using humor, several participants discussed the importance of the context or discussion which humor was used.

Participant 7 (F, C) said: "As long as it fits the context of what we're talking about and it's not something random or way out of left field, then usually it gets a good reaction and people will laugh."

Participant 13 (M, C) stated: "I usually just like to keep on the discussion of what we're talking about. If it's something that makes people laugh and that's in the realm of what we're talking about, I guess you could consider that a joke, but I don't go out of my way to make a joke."

Participants also discussed their reaction or the class's reaction. One participant felt his 
commentary was received positively.

Participant 12 (M, C) stated "They would laugh. Maybe there might have been some student reactions from time the professor left the class, but for the most part, I feel like there wasn't any negative reactions."

In contrast, female participants stated male humor can be viewed as impassive, annoying, or to show a desire to be heard.

Participant 4 (F, AA) said: "They [females] either just won't care or they might just give them a dirty look. I think sometimes they might join, but most of the time they'd just be annoyed by it."

Participant 6 (F, C) stated: “I think it comes back to maturity. I don't know if I've ever thought about it deep enough to wonder what their intentions are. Just stupidity comments more or less. Not stupid that they're bad comments, just you're just talking to talk, to hear a little laugh and lighten the mood more or less. You obviously just wanted your voice to be heard."

Participant 7 (F, C) said: "I feel like females don't care as much about that."

\section{Siblings \& Comfortability with the Opposite Sex}

Participants discussed their level of comfortability with peers of the opposite sex, specifically noting that their upbringing with opposite-sex siblings impacted their level of comfortability.

Half of the participants who mentioned this, had older siblings of the opposite sex. Participant 8 (F, C) said: "Yes, I have and older brother and a younger sister." Participant 11 (M, C) stated: "I grew up with a just a mom and a sister and I don't want to seem like an overly aggressive almost, saying like "you do this, you do this." Participant 13 (M, C) said: "I probably feel that way just because of the way that I've grown up. I've grown up with two older sisters."

Participants who did have an opposite-sex sibling also stated they felt more exceptional to relate to and have comfortability with their opposite-sex peers because of their upbringing.

Participant 2 (F, C): stated "Based off of my origin and my background, I grew up with all brothers. So I'm more comfortable associating with males than I am females."

Participant 8 (F, C) said: "Probably, just because growing up my brother had other boys in the house, as well. And they were always older than me, so, I think that contributed to my comfort level, in that sense." 
Participant 13 (M, C) stated: “When I was younger growing up with my two sisters, they'd always have their friends over who were female. So just being around them and being in that environment growing up made me much more comfortable." 


\section{CHAPTER 5 \\ DISCUSSION}

This study aimed to explore how gender imbalance can impact upper-level public relations students, and what similarities or differences exist with other single-gender dominant programs, such as nursing and STEM. This study found six emerging themes, including female-to-female reliance, female-to-female competitiveness, female leadership, perceived low male work ethic, male humor, and siblings and comfortability with the opposite sex. The findings showed that upper-level public relations students do encounter social challenges because five of the 10 challenges are related to those experienced by male nurse and female STEM students. The study showed that male nursing and public relations students shared more similarities, and thus encountering more challenges while male STEM and female public relations students shared leadership and behavior qualities, which were considered less detrimental.

There were three research questions presented in this study. The first research question asked how the gender majority status impact female public relations student's social learning outcomes. The results suggest that females rely on their gender, are competitive in academic and professional opportunities, and are likely to hold leadership positions in group work.

The second research question asked how the gender minority status of males impacted their social learning outcomes, and the emerging themes suggest a perceived low male work ethic and use of humor in the classroom.

The third research question asked how the gender imbalance in the public relations classroom is similar or different to nursing and STEM education literature. The study found that male public relations students share similar three challenges with male nursing students in academic excellence, loneliness, humor, and independence in group work. As it exemplified adversities for minority group members, these findings aligned with tokenism (Kanter, 1977;

Hirshfield, 2015). As the study suggests, male public relations students shared more similar challenges with male nurses and may encounter greater adversities.

Besides, it was inferred that female public relations students shared two findings with male STEM students in addressing their likelihood of leadership and engaging in masculine behaviors. These findings coincide with role congruity theory, which examines traditional roles and female 
leadership in single-gender dominant environments (Eagly \& Karau 2002; Garcia-Retamero \& Lopez-Safra, 2006).

\section{Similarities and Differences to Nurse and STEM Programs}

This study showed that five of the 10 challenges in nursing and STEM education literature were shown to be experienced by upper-level public relations students.

The role strain dimension had two notable findings. First, male nursing students face social stigma, such as toning down masculine attributes (i.e., "competitiveness or assertiveness" to prevent scrutiny from their instructor or peers (Wilson, 2005; Dyck et al., 2009, p. 650). This finding was not similar to male public relations students but was shown to be the opposite in female students. The emerging theme female-to-female competitiveness shows that females PR students competitive in attaining academic or professional success and desired to stand out from their female peers. This finding is different from male nursing students in that being scrutinized for this behavior was not explicitly found with this phenomenon. As male nursing students are expected to tone down their masculine behaviors, there is an interesting dichotomy in that female public relations students expresses these attributes without negative consequences. This finding aligns with role congruity theory in that female public relations students are engaging in masculine traits, which are shown to be more successful in attaining leadership roles (Eagly \& Karau, 2002; Garcia-Retamero \& Lopez-Safra, 2006). Although this behavior may be perceived poorly in a professional setting (Johnson, Murphey, Zewdie, Reichard, 2008), this study also did not explicitly find consequences for females taking on masculine traits, which may be caused by the female-dominant environment.

Second, female STEM students often focused on their grades, including additional time spent on assignments or attended their instructor's office hours for "affirmation" in their abilities (Kanter, 1977; Dingel, 2006, p. 163). Except for attending office hours (which was not explicitly mentioned), female public relations students focused on their grades by dedicating additional time spent on coursework in group work activities (see Perceived Low Male Work Ethic). This finding supports that in both male- and female-dominant programs, female students prioritize their grades or desire to achieve academic excellence. This finding displayed tokenism because females in STEM experienced "performance pressure" where they had to work harder as an externality (Kanter, 1977; Hirshfield, 2015, p. 2058). 
The next dimension focuses on teamwork activities, which showed three similar and dissimilar findings. First, male nursing students "experienced loneliness or isolation," which may apply to group activities (Kelly et al., 1996; p. 41; MacWilliams et al., 2013). This study found that male public relations students also experience this, specifically in team discussions. Participants discussed that females were more receptive to other female's input than they were with male peers (see Female Leadership). It can be inferred that in female-dominant programs, males may experience loneliness as their contributions are less reciprocated in group activities. Female STEM students were also found to experience loneliness, especially as they perceive to be offered less intensive work in group activities (Seron et al., 2018; Carter, 2019). This experience is shared by male students, as female public relations students perceived themselves as the most involved and cited males' academic struggles (see Perceived Low Male Work Ethic). Male assignments may be considered less intensive as they are perceived to have a low work ethic, including project involvement. The experiences of loneliness found in female STEM, male nurse, and public relations students are consistent with "boundary heightening" where minority groups may be excluded from activities from their peers (Kanter, 1977; Hirshfield, 2015, p. 2058). It can be noted that in a female-dominant environment, males are more likely to encounter this challenge, as it appeared in both nursing and public relations programs.

Second, male nursing students are succumbed to holding "leadership" positions by their female peers (Anthony, 2004; Dyck et al., 2009, p. 650). This study found the opposite, as participants stated, males did not show interest in (i.e., lack of knowledge or to avoid negative perception by peers) nor were explicitly compelled to attain a leadership role. However, participants stated that females held more leadership roles because of their interest or perceived leadership qualities (see Female-to-Female Leadership). Additionally, females may not be succumbed to holding this role because they experienced competitiveness with other females in academic and professional opportunities (see Female-to-Female Competitiveness). Males in STEM are also more likely to both desire and have leadership roles (Eddy et al., 2015). This study did not support this in males; rather, female public relations students were more likely to show interest or have a leadership role. It can be inferred that in the desire for leadership in female public relations students most closely aligns with the motivations presented by male STEM students. This finding is observed in role congruity theory, were not adhering to traditional gender roles can result in being perceived poorly as a female, also known as 
prescriptive bias (Johnson et al., 2008). However, as the theory posits, in an environment dominated with female presence, this was not explicitly shown to be consequential to female public relations students.

Third, male nursing students are independent and less likely to collaborate in group activities (Sedgwick \& Kellett, 2015). This study showed that males are perceived to struggle because they may be less motivated or willing to spend additional time on their assignments (see Perceived Low Male Work Ethic). In these instances, males may be more independent because their female peers are less receptive to their input (see Female Leadership) therebye impacting their willingness to collaborate. This represents "boundary heightening" in tokenism because females have shown to be less receptive to males' ideas in brainstorming activities (see Female Leadership) (Kanter, 1977; Dingel, 2006, p. 163). This causes challenges for males, as they will either manage their identity or attempt to blend into their community (Zimmer, 1988). It can be inferred that in a female-dominant environment, male nursing and public relations students may struggle academically by being less engaged in group activities.

The final dimension, overall social environment, showed one similar finding. Male nursing students engaged in discussions by making jokes or entertaining the classroom (Dyck et al., 2009) was also prevalent in male public relations students' behavior. They also made jokes using classroom contexts (see Male Humor). As they are minority group members, this behavior is closely associated with "performance pressure," to which not only do these members stand out, they do so by entertaining the classroom (Kanter, 1977; Dingel, 2006, p. 163; Hirshfield, 2015, p. 2058). It should be noted that this form of tokenism is also associated with "boundary heightening," to which not only do male students struggle academically, their performance is also affected (Ehrlich-Martin, 1980; Zimmer, 1988; Hirshfield, 2015, p. 2058). For example, the study found male humor in the public relations classroom was received poorly by females. Accordingly, males may use humor as an attempt to recoup these negative consequences. This finding advances what we know of male humor in male nurses in that we understand how it is used (in-class contexts) as well as the reactions of female peers (received negatively). With the exception of finding male humor occurred for both male nurses (Dyck et al., 2009) and male public relations students, the overall social environment dimension showed the least matches to nursing and STEM education literature.

This study showed that male and female public relations students experienced social 
challenges, however, it was apparent that male students had greater disadvantages. Three of the five findings were directly related to male nurses which addressed loneliness, independence, and use of humor. A recent study supported this, as junior and senior standing male students perceived a lack of inclusivity (Brown et al., 2019). This can have negative consequences, as they may perceive less value in the learning outcomes or an overall positive experience in the classroom (Garbay, 2015; Brown et al., 2019). The two remaining findings addressed female challenges, which were more consistent with male STEM student behaviors. This study found that female public relations students often obtained leadership roles and engaged in masculine behaviors. Brown et al. (2019) also supported this, as female public relations students had greater opportunities for leadership. This study did not explicitly find consequences for females engaging in masculine behaviors which was shown in male nurses. As the study supported females compete with other females, the female-dominant environment may encourage female students to engage in these behaviors to become successful in academic and career opportunities.

This study found one theme, Siblings and Comfort with the Opposite Sex (see Findings) that did not match the theories posited (i.e., tokenism or role congruity theory). As it centers around student's social development before college, it does not align with group minority or leadership challenges. This suggests that students' social development with family and siblings may affect their level of comfort interacting with the opposite sex. Research addressing public relations students' experiences before college, and their home life is also a relatively unexplored area and may provide a better understanding of this unique phenomena.

\section{Study Limitations}

Following the data findings, there are noted limitations beyond the researcher's bias (see Methodology). First, the discussions made are considered a limitation because the research was conducted and presented by a new scholar (Research Methodology, n.d.). Second, the research on undergraduate public relations student social challenges related to gender is a relatively new area and is considered exploratory research (USC Libraries, n.d.). In order to become explanatory, subsequent studies should investigate further (USC Libraries, n.d.).

In developing a new aim of the research, there are two ways to improve the accuracy of the results and understand the phenomena further. First, the findings may also be considered unreliable. For example, female public relations students shared similarities with male STEM 
students in leadership, which was dissimilar to male nurses with leadership roles (USC Libraries, n.d.). Accordingly, future research should align these findings, which can potentially yield more accurate results. Second, this study examined what types of consequences may occur for public relations students and not precisely how they can cause adverse effects during their college experiences. In developing the interview protocol, future research should focus on how students believe these social experiences have impacted their academic careers (Research Methodology, n.d.).

Several limitations that may improve the methodology. First, this data was collected, analyzed, and interpreted by the researcher, leading a potential self-reported bias (USC Libraries, n.d.). Second, this study initially anticipated each interview session to last approximately 20 minutes. However, the sessions lasted between 20 and 55 minutes. Future studies should extend the session time to provide a more accurate description of the data collection processes. Third, this study originally intended to have a maximum of 24 male and female (12 each) participants (see Methodology and APPENDIX B). Nevertheless, the sample featured three males, nine females, and one gender-nonconforming female-presenting student. In order to get a rounded understanding of this phenomenon, it is encouraged that future studies will recruit more males (Research Methodology, n.d.). Fourth, this study did not recruit or collect data from public relations instructors. The data is only representative of the students' point of view and subsequent studies incorporating instructors can provide a critical angle to the study findings.

\section{Future Directions}

There are several future directions for potential replicative and original research studies. In replicative approaches, it is recommended to incorporate more male participants to develop a more rounded understanding of their perspectives. Scholars can also use the recommended theoretical lens to build upon the literature presented to confirm or disprove its applicability to upper-level public relations students.

There are several ways scholars can build or upon the phenomena found. First, the participants were exclusively junior and senior standing public relations students. Previous literature from nursing and STEM programs have data samples from all academic ranks (Eddy \& Brownell, 2016). Future research should also include freshmen, sophomore, or graduate students to see if there are any similarities or differences. Second, research can focus on how the study 
findings can be consequential to students in the classroom as well as when they transition to the professional world. Third, the study found that female public relations students subscribed to male STEM students in masculine behaviors yet did not explicitly find a penalty for this - which would be an area to investigate further. Fourth, it is recommended that future qualitative studies incorporate public relations instructors to round our understanding of the issues presented in this study. 


\section{CHAPTER 6 \\ CONCLUSION}

Despite three decades of literature have explored the gender imbalance of public relations at a professional level (Toth, Aldoory, \& Sha, 2006; Geyer-Semple, 2012; Vardeman-Winter \& Place, 2017), there is a dearth of information addressing if or how these experiences are informed at the collegiate level. Previous studies have inferred that public relations students' social challenges exist (Waymer et al., 2018; Brown et al., 2019). This study aimed to determine how the gender imbalance impacts upper-level public relations students, and what similarities or differences are associated with other single-gender dominant programs, such as nursing and STEM. Using three dimensions (i.e., role strain, teamwork, and overall social environment) found in both programs, this study emerged six themes including female-to-female reliance, female-to-female competitiveness, female leadership, perceived low male work ethic, male humor, and siblings and comfort with the opposite sex. Of these themes, five were found to be related to those experienced by nursing and STEM students.

This study presented three research questions. In response to the first research question which asked how the gender majority status impacts female public relations students, the results of the study suggest females rely on their gender, are competitive in academic and professional opportunities, and are likely to hold leadership positions in group work.

In response to the second question which asked how the gender minority of status impacted their social learning outcomes, the results of the study suggest a perceived low male work ethic (i.e., less contributions and effort) and use of humor in the classroom (i.e., classroom contexts and peer reactions).

In response to the third research question which asked about the similarities and differences between nursing and STEM programs, this study showed that male public relations students share similar three challenges with male nursing students in academic excellence, loneliness, humor, and independence in group work. These findings aligned with tokenism because they exemplified adversities for minority group members (Kanter, 1977; Hirshfield, 2015). Furthermore, female public relations students shared two findings with male STEM students in addressing their likelihood of leadership and engaging in masculine behaviors. Role congruity theory coincided with this, as it examines traditional roles and leadership in singlegender dominant fields (Eagly \& Karau 2002; Garcia-Retamero \& Lopez-Safra, 2006). 
Both theories presented detrimental effects to groups that encounter them. Students experiencing tokenism can encounter "performance pressure" that can lead to caution about achievements in an attempt to deter recognition, "boundary heightening" which can result in internalized judgement or rejection of their identity, and "role entrapment" when they engage in "stereotypical" behaviors to blend into the community (Kanter, 1977; Dingel, 2006; Hirschfield, 2015, p. 2058; Hu, 2019, p. 19). Role congruity theory addressed females are less capable to become leader, or under this role are viewed as "less favorable" than a male leader (Eagly \& Karau, 2002, p. 588). It can result in a lack of female presence in leadership or engaging in masculine traits (which defies traditional roles) leading to her to be judged poorly (Johnson et al., 2008).

Future studies should continue to focus on student social experiences because they have shown to affect attrition rates and pursuing graduate degrees in single-gender dominant programs (Astin \& Sax, 1996; Morris, 2007; Gayles \& Ampaw, 2014). The interactions in college can also set the tone for professional environments, including social structures and relationships. By addressing the current status, fields can retain gender minority students and build toward a gender-balanced program and field in the future (Blickenstaff, 2005; Gillen \& Tanenbaum, 2014; Eddy \& Brownell, 2016). 


\section{REFERENCES}

Abshire, D. A., Graves, J. M., Roberts, M. L., Katz, J., Barbosa-Leiker, C., \& Corbett, C. F. (2018). Student support in accelerated nursing programs: Gender-based perspectives and impact on academic outcomes. Nursing Outlook, 66(1), 84-93.

https://doi.org/10.1016/j.outlook.2017.08.010

Aldoory, L. (1998). The language of leadership for public relations professionals. Journal of Public Relations Research, 10(2), 72- 101.

https://doi.org/10.1207/s1532754xjprr1002_01

Aldoory, L., \& Toth, E. (2002). Gender discrepancies in a gendered profession: A developing theory for public relations. Journal of Public Relations Research, 14(2), 103-126. https://doi.org/10.1207/S1532754XJPRR1402_2

Aldoory, L., \& Toth, E. (2004). Leadership and gender in public relations: Perceived effectiveness of transformational and transactional leadership styles. Journal of Public Relations Research, 16, 157-183. DOI: 10.1207/s1532754xjprr1602_2

Allen, K. (2016). The Need for More Women in Power. Public Relations Society of America. Retrieved 27 February 2020 from https://apps.prsa.org/Intelligence/Tactics/Articles/view/11548/1128/The_Need_for_More _Women_in_Power\#.XlgvXBNKjqR.

Altermatt, E. R., Jovanovic, J., \& Perry, M. (1998). Bias or responsivity? Sex and achievement-level effects on teachers' classroom questioning practices. Journal of Educational Psychology, 90(3), 516. https://doiorg.www.libproxy.wvu.edu/10.1037/0022-0663.90.3.516

American Association of Colleges of Nursing. (2015). Enhancing diversity in the workforce. Washington, DC: American Association of Colleges of Nursing.

Anthony, A.S. (2004). Gender bias and discrimination in nursing education: Can we change it? Nurse Educator, 29, 121-125. https://doi.org/10.1097/00006223-200405000-00011

Astin, H. S., \& Sax, L. J. (1996). Developing scientific talent in undergraduate women. In c. davis, A. B. ginorio, c. s. hollenshead, B. B. lazarus, p. m. Rayman, \& Associates (eds.). The equity equation: Fostering the advancement of women in the sciences, mathematics, and engineering (pp. 96-121). San Francisco: Jossey-Bass. 
Austin, L. L. (2010). Framing diversity: A qualitative content analysis of public relations industry publications. Public Relations Review, 36(3), 298-301. https://doi.org/10.1016/j.pubrev.2010.04.008

Bartfay, W.J., Bartfay, E., Clow, K.A., \& Wu,T. (2010). Attitudes and perceptions towards men in nursing education. The Internet Journal of Allied Health Sciences and Practice, 8(2), $1-7$.

Baumeister, R.F., \& Leary, M.R. (1995). The need to belong: Desire for interpersonal attachments as a fundamental human motivation. Psychological Bulletin, 117, 497-529.

Bear, J. B., \& Woolley, A. W. (2011). The role of gender in team collaboration and performance. Interdisciplinary science reviews, 36(2):146-153. https://doi.org/10.1179/030801811X13013181961473

Beer, C. T., \& Darkenwald, G. G. (1989). Gender differences in adult student perceptions of college classroom social environments. Adult Education Quarterly, 40(1), 33- 42. doi:10.1177/07417368904000104.

Bell-Scriber, M.J. (2008). Warming the nursing education climate for traditional-age learners who are male. Nursing Education Perspectives, 29, 143-150.

Brady, K. L., \& Eisler, R. M. (1999). Sex and gender in the college classroom: A quantitative analysis of faculty-student interactions and perceptions. Journal of Educational Psychology, 91(1), 127. http://dx.doi.org.www.libproxy.wvu.edu/10.1037/00220663.91 .1 .127

Bravo, R., Lucia-Palacios, L., \& Martin, M. J. (2016). Processes and outcomes in student teamwork. An empirical study in a marketing subject. Studies in Higher Education, 41(2), 302-320. https://doi.org/10.1080.03075079.2014.926319

Britton, E., Simper, N., Leger, A., \& Stephenson, J. (2017). Assessing teamwork in undergraduate education: a measurement tool to evaluate individual teamwork skills. Assessment \& Evaluation in Higher Education, 42(3), 378-397. https://doi.org/10.1080/02602938.2015.1116497.

Brown, K. A., Waymer, D., \& Zhou, Z. (2019). Racial and gender-based differences in the collegiate development of public relations majors: Implications for underrepresented recruitment and retention. Journal of Public Relations Education, 5(1), 1-30. https://doiorg.www.libproxy.wvu.edu/10.1016/j.pubrev.2011.09.017 
Burgess, D., \& Borgida, E. (1999). Who women are, who women should be: Descriptive and prescriptive gender stereotyping in sex discrimination. Psychology, Public Policy, and Law, 5, 665-692. https://doi.org/10.1037/1076-8971.5.3.665

Burns, C., \& Myhill, D. (2004). Interactive or inactive? A consideration of the nature of interaction in whole class teaching. Cambridge Journal of Education, 34(1), 35-49. https://doi.org/10.1080/0305764042000183115

Carter, D. F., Dueñas, J. E. R., \& Mendoza, R. (2019). Critical Examination of the Role of STEM in Propagating and Maintaining Race and Gender Disparities. In Michael B. Paulsen, Laura W. Perna, (Eds.) Higher Education: Handbook of Theory and Research (pp. 39-97). New York: Springer. https://doi.org/10.1007/978-3-030-03457-3_2

Chen, X., \& Soldner, M. (2013). STEM attrition: College students' paths into and out of STEM fields (NCES 2014-001). Washington, DC: National Center for Education Statistics, Institute of Education Sciences, US Department of Education. Institute for Education Sciences, US Department of Education.

Cheryan, S., Plaut, V. C., Davies, P. G., \& Steele, C. M. (2009). Ambient belonging: how stereotypical cues impact gender participation in computer science. Journal of Personality and Social Psychology, 97(6), 1045. https://doi.org/10.1037/a0016239

Cheryan, S., \& Plaut, V. C. (2010). Explaining underrepresentation: a theory of precluded interest. Sex Roles, 63, 475-488. doi:10.1007/s11199-010-9835-x.

Cheryan, S., Master, A., \& Meltzoff, A. N. (2015). Cultural stereotypes as gatekeepers: Increasing girls' interest in computer science and engineering by diversifying stereotypes. Frontiers in Psychology, 6, 49.

Cho, J. Y., \& Lee, E. H. (2014). Reducing confusion about grounded theory and qualitative content analysis: Similarities and differences. The qualitative report, 19(32), 1. Retrieved from https://nsuworks.nova.edu/tqr/vol19/iss32/2

Clark Blickenstaff, J. (2005). Women and science careers: leaky pipeline or gender filter?. Gender and Education, 17(4), 369-386. https://doi.org/10.1080/09540250500145072 Cline, C.; Smith, H., Johnson N.; Toth, E.; \& Turk, J.V.S. (1986). The velvet ghetto: The impact 
of the increasing percentage of women in public relations and business communication. IABC Foundation, San Francisco, CA.

Connell, R.W. (1995). Masculinities. Los Angeles: University of California Press Berkley.

Crawford, M., \& MacLeod, M. (1990). Gender in the college classroom: An assessment of the “chilly climate" for women. Sex Roles, 23(3-4), 101-122. https://doi.org/10.1007/BF00289859

Creswell, J. (2013). Qualitative inquiry \& research design: Choosing among five approaches (Third ed.). Los Angeles: SAGE Publications.

Collinson, D. and J. Hearn (1994). Naming Men as Men: Implications for Work, Organisation and Management, Gender, Work and Organisation, 1(1), pp. 2-20. https://doi.org/10.1111/j.1468-0432.1994.tb00002.x

Corbin, L., \& Strauss, A. (2007). Basics of qualitative research: Techniques and procedures for developing grounded theory (3rd ed.). Thousand Oaks, CA: Sage. https://doi.org/10.4135/9781452230153

Cundiff, J. L., Vescio, T. K., Loken, E., \& Lo, L. (2013). Do gender-science stereotypes predict science identification and science career aspirations among undergraduate science majors?. Social Psychology of Education, 16(4), 541-554. https://doi.org/10.1007/s11218-013-9232-8

Curtin, P. A., \& Gaither, T. K. (2006). Contested notions of issue identity in international public relations: A case study. Journal of Public Relations Research, 18(1), 67-89. https://doi.org/10.1207/s1532754xjprr1801_4.

Darkenwald, G. G., \& Gavin, W. J. (1987). Dropout as a function of discrepancies between expectations and actual experiences of the classroom social environment. Adult Education Quarterly, 37(3), 152-163. doi:10.1177/0001848187037003003.

Diekman, A. B., \& Goodfriend, W. (2004). Injunctive norms as role-based evaluations. Unpublished manuscript, Miami University, Oxford OH.

Dingel, M. J. (2006). Gendered experiences in the science classroom. Removing barriers: Women in academic science, technology, engineering, and mathematics, 161-178.

Dozier, M. D., \& Sha, B. (2013). Why women earn less than men: The cost of gender discrimination in U.S. public relations. Public Relations Journal, 7(1 , 1-21.

Dyck, J., Oliffe, J., Phinney, A., \& Garrett, B. (2009). Nursing instructors' and male nursing 
students' perceptions of undergraduate, classroom nursing education. Nurse Education Today, 29(6), 649-653. doi:10.1016/j.nedt.2009.02.003.

Eagly, A.H. (1987). Sex Differences in Social Behavior: A Social-Role Interpretation. Hillsdale, NJ: Erlbaum.

Eagly, A. H., \& Diekman, A. B. (2004). What is the problem? Prejudice as an attitude-incontext. In J. F. Dovidio, P. Glick \& L. A. Rudman (Eds.), Reflecting on the Nature of Prejudice.

Eagly, A., \& Diekman, A. (2004). Of men, women and motivation: A role congruity account. Institute for Policy Research, Northwestern University, Working Paper Series.

Eagly, A. H., \& Karau, S. J. (2002). Role congruity theory of prejudice toward female leaders. Psychological review, 109(3), 573. https://doi.org/10.1037/0033-295X.109.3.573

Eagly, A. H., \& Steffen, V. J. (1984). Gender stereotypes stem from the distribution of women and men into social roles. Journal of Personality and Social Psychology, 46(4), 735. https://doi.org/10.1037/0022-3514.46.4.735

Eagly, A. H., \& Steffen, V. J. (1986). Gender stereotypes, occupational roles, and beliefs about part-time employees. Psychology of Women Quarterly, 10(3), 252-262. https://doi.org/10.1111/j.1471-6402.1986.tb00751.x

Eagly, A. H., Wood, W., \& Diekman, A. B. (2000). Social role theory of sex differences and similarities: A current appraisal. The developmental social psychology of gender, 12, 174.

Eddy, S. L., Brownell, S. E., \& Wenderoth, M. P. (2015). Gender gaps in achievement and participation in multiple introductory biology classrooms. CBE-Life Sciences Education, 13(3), 478-492. https://doi.org/10.1187/cbe.13-10-0204

Eddy, S. L., \& Brownell, S. E. (2016). Beneath the numbers: A review of gender disparities in undergraduate education across science, technology, engineering, and math disciplines. Physical Review Physics Education Research, 12(2), 020106. https://doi.org/10.1103/PhysRevPhysEducRes.12.020106

Edwards, L. (2011). Diversity in public relations. In L. Edwards, \& C. E. Hodges (Eds.), Public relations, society \& culture: Theoretical and empirical explorations (pp. 87-101). New York, NY: Routledge. https://doi.org/10.4324/9780203832134

Edwards, K. L. (2014). Role strain theory and understanding the role of head clergy of racially diverse churches. Sociology of Religion, 75, 57-79. https://doi.org/10.1093/socrel/srt047 
Ellis, D.M., Meeker, B.J., \& Hyde, B.L. (2006). Exploring men's perceived educational experiences in a baccalaureate program. Journal of Nursing Education, 45, 523-527. https://doi.org/10.3928/01484834-20061201-09

Ely, R. J. (1994). The effects of organizational demographics and social identity on relationships among professional women. Administrative Science Quarterly, 39, 203-238. https://doi.org/10.2307/2393234

Ely, R. J. (1995). The power in demography: Women's social constructions of gender identity at work. Academy of Management Journal, 38, 589- 634. https://doi.org/10.2307/256740

Evans, J.A., \& Frank, B. (2003). Contradictions and tensions: Exploring relations of masculinities in the numerically female-dominated nursing profession. The Journal of Men's Studies, 11, 277-292. https://doi.org/10.3149/jms.1103.277

Fencl, H., \& Scheel, K. R. (2006). Making sense of retention: An examination of undergraduate women's participation in physics courses. Removing barriers: Women in academic science, technology, engineering, and mathematics, 287-302.

Fenwick, G. D., \& Neal, D. J. (2001). Effect of gender composition on group performance. Gender, Work \& Organization, 8(2), 205-225. https://doi.org/10.1111/1468-0432.00129

Fister, S. G. (1999). Men students' experiences in nursing education (Doctoral dissertation, University of Kentucky).

Fitch, K., James, M., \& Motion, J. (2016). Talking back: Reflecting on feminism, public relations and research. Public Relations Review, 42(2), 279-287. https://doi.org/10.1016/j.pubrev.2015.05.006

Fitch, K., \& Third, A. (2010). Working girls: Revisiting the gendering of public relations. Prism, 7(4), 1-13. http://researchrepository.murdoch.edu.au/id/eprint/4006

Friedel, J. M., Cortina, K. S., Turner, J. C., \& Midgley, C. (2007). Achievement goals, efficacy beliefs and coping strategies in mathematics: the role of perceived parent and teacher goal emphases. Contemporary Educational Psychology, 32, 434-458. doi:10.1016/j.cedpsych.2006.10.009.

Fuller, A. (2010). Female undergraduates continue to outnumber men, but gap holds steady. The Chronicle of Higher Education. Retrieved April 14, 2020 from http://chronicle.com/article/Female-Undergraduates-Continue/63726/.

Fusch, P. I., \& Ness, L. R. (2015). Are we there yet? Data saturation in qualitative research. The 
qualitative report, 20(9), 1408. Retrieved from

http://www.libproxy.wvu.edu/login?url=https://search-proquest-

com.www.libproxy.wvu.edu/docview/1721368991?accountid=2837

García-Retamero, R. (2006). Identidad de género y nivel de aspiraciones profesionales en alumnos universitarios. Revista Mexicana de Psicología, 23(2), 217-224.

García-Retamero, R., \& López-Zafra, E. (2006). Congruencia de rol de género y liderazgo: el papel de las atribuciones causales sobre el éxito y el fracaso. Revista Latinoamericana de Psicología, 38(2), 245-257.

Garibay, J. C. (2015). STEM students' social agency and views on working for social change: Are STEM disciplines developing socially and civically responsible students?. Journal of Research in Science Teaching, 52(5), 610-632. https://doi.org/10.1002/tea.21203

Gayles, J. G., \& Ampaw, F. (2014). The impact of college experiences on degree completion in STEM fields at four-year institutions: Does gender matter?. The Journal of Higher Education, 85(4), 439-468. https://doi.org/10.1353/jhe.2014.0022

Geis, F. L. (1993). Self-fulfilling prophecies: A social psychological view of gender. In A. E. Beall \& R. J. Sternberg (Eds.), The Psychology of Gender (p. 9-54). New York, NY: Guilford Press.

Geis, F. L. (1993). Self-fulfilling prophecies: A social psychological view of gender. In A. E. Beall \& R. J. Sternberg (Eds.), The Psychology of Gender (p. 9-54). New York: Guilford Press.

Geyer-Semple, V. (2012). Through classroom walls: A collaborative public relations education for creating integrated, digital media campaigns. Communication Teacher, 26(1), 37-44. doi:10.1080.1740 4622.2011.625364.

Glick, P. (1991). Trait-based and sex-based discrimination in occupational prestige, occupational salary, and hiring. Sex Roles, 25(5-6), 351-378. https://doi.org/10.1007/BF00289761

Gibbons, S. J., Grunig, L. A., Toth, E. L., \& Hon, L. C. (2001). Women in public relations: How gender influences practice. Public Relations Review, 27(3), 369-369. https://doi.org/10.1016/S0363- 8111(01)00093-5.

Gillen, A., \& Tanenbaum, C. (2014). Exploring gender imbalance among STEM doctoral degree recipients. Washington, DC: American Institutes for Research. 
https://www.air.org/sites/default/files/downloads/report/STEM\%20PhDs\%20Gender\%20 Imbalance\%20Sept\%202014c.pdf

Good, C., Rattan, A., \& Dweck, C. S. (2012). Why do women opt out? Sense of belonging and women's representation in mathematics. Journal of personality and social psychology, 102(4), 700. https://doi.org/10.1037/a0026659

Goode, W. J. (1960). A theory of role strain. American Sociological Review, 25, 483-496. https://doi.org/10.2307/2092933

Gotlieb, M. R., McLaughlin, B., \& Cummins, R. G. (2017). 2015 survey of journalism and mass communication enrollments: Challenges and opportunities for a changing and diversifying field. Journalism \& Mass Communication Educator, 72(2), 139153.https://doi.org/10.1177/1077695817698612

Gower, K. K. (2017). The Historiography of North American Public Relations. In North American Perspectives on the Development of Public Relations (pp. 113-126). London, UK: Palgrave Macmillan, London.

Grounded Theory Institute (2013). What is grounded theory? Retrieved from http://www.groundedtheory.com/what-is-gt.aspx

Groat, L., \& Wang, D. (2002). Architectural research methods. New York, NY: Wiley \& Sons. Grunig, L. A., Toth, E. L., \& Hon, L. C. (2001). Women in public relations. How gender influences practice. New York, NY: Routledge

Heilman, M. E. (2001). Description and prescription: How gender stereotypes prevent women's ascent up the organizational ladder. Journal of Social Issues, 57, 657-674. https://doi.org/10.1111/0022-4537.00234

Hirshfield, L. E. (2015). Tokenism. The Wiley Blackwell Encyclopedia of Race, Ethnicity, and Nationalism, 1-3. https://doi.org/10.1002/9781118663202.wberen199

Hodges, E., Rowsey, P., Gray, T., Kneipp, S., Giscombe, C., Foster, B., . . Kowlowitz, V. (2017). Bridging the gender divide: Facilitating the educational path for men in nursing. The Journal of Nursing Education, 56(5), 295-299. doi:10.3928/01484834-20170421-08.

The Holmes Report. (2015). World PR Report: Executive Summary. Retrieved February 27, 2020 from https://www.provokemedia.com/ranking-and-data/world-prreport/analysis/executive-summary.

Hon, L. (1995). Towards a feminist theory of public relations. Journal of Public Relations 
Research, 7(1), 27-88. https://doi.org/10.1207/s1532754xjprr0701_03

Horsley, S. J. (2009). Women's contributions to American public relations, 1940-1970. Journal of Communication Management, 13(2), 100-115. https://doi.org/10.1108/13632540910951731

Hu, Y. (2019). Assessing the Impact of Gender and Racial/Ethnic Composition on Women of Color Students' Likelihood to Pursue a Doctoral Degree in Stem Disciplines. http://hdl.handle.net/2022/24977

Hughes, R. L., \& Jones, S. K. (2011). Developing and assessing college student teamwork skills. New Directions for Institutional Research, 2011(149), 53-64. https://doi.org/10.1002/ir.380 Institute of Medicine. (2010). The Future of Nursing: Leading Change, Advancing Health. Washington, DC: National Academies Press. Jackson, J. E. (1990). I am a Fieldnote: Fieldnotes as a Symbol of Professional Identity'. Edited by Sanjek Roger. Field Notes: The Making of Anthropology.

Jackson, L. A., \& Sullivan, L. A. (1990). Perceptions of multiple role participants. Social Psychology Quarterly, 274-282. https://doi.org/10.2307/2786965

Johnson, S. K., Murphy, S. E., Zewdie, S., \& Reichard, R. J. (2008). The strong, sensitive type: Effects of gender stereotypes and leadership prototypes on the evaluation of male and female leaders. Organizational Behavior and Human Decision Processes, 106(1), 39-60. https://doi.org/10.1016/j.obhdp.2007.12.002

Jones, M., \& Alony, I. (2011). Guiding the use of grounded theory in doctoral studies-An example from the Australian film industry. https://doi.org/10.28945/1429

Judd, P. C., \& Oswald, P. A. (1997). Employment desirability: The interactive effects of gender-typed profile, stimulus sex, and gender-typed occupation. Sex Roles, 37(7-8), 467476. https://doi.org/10.1023/A:1025669801166

Kanack, M. (2011). College STEM Students' Perspectives on Sexism and Sexist Humor. Undergraduate Honors Theses. 647. https://scholar.colorado.edu/honr_theses/647

Kanter, R. M. (1977). Men and women of the corporation Basic Books. New York.

Kanter, R. (1977). Some Effects of Proportions on Group Life: Skewed Sex Ratios and Responses to Token Women. American Journal of Sociology, 82(5), 965-990. Retrieved from http://www.jstor.org/stable/2777808 https://doi.org/10.1086/226425

Kelly, N. R., Shoemaker, M., \& Steele, T. (1996). The experience of being a male student nurse. 
Journal of Nursing Education, 35(4), 170-174.

Kim, H.S. (2002). We talk, therefore we think? A cultural analysis of the effect of talking on thinking. Journal of Personality and Social Psychology, 83, 828-842. https://doi.org/10.1037/0022-3514.83.4.828

Kim, H.S. (2008). Culture and the cognitive and neuroendocrine responses to speech. Journal of Personality and Social Psychology, 94, 32-47. https://doi.org/10.1037/0022-3514.94.1.32

King, E. B., Hebl, M. R., George, J. M., \& Matusik, S. F. (2010). Understanding tokenism: Antecedents and consequences of a psychological climate of gender inequity. Journal of Management, 36(2), 482-510. https://doi.org/10.1177/0149206308328508

King, J., Maniam, B., \& Leavell, H. (2017). Shattered Glass and Creaky Steps: Remodeling the Glass Ceiling and Glass Escalator Theories Using an Intersectional Toolbox. Southern Journal of Business and Ethics, 9, 194-203.

King-Spezzo, A. J. (2017). Adult Learners' Expectations of Ideal Course Environments Based on the Adult Classroom Environment Scale (Doctoral dissertation, Valdosta State University).

Kubanek, Anne-Marie Weidler, and Margaret Waller. (1996). Confidence in Science: Interpersonal and Institutional Influences. Ste.-Anne-de-Bellevue, Quebec: John Abbott College.

Krugler, E. (2017). Women in public relations: The influence of gender on women leaders in public relations. Graduate Theses and Dissertations. 15555. https://lib.dr.iastate.edu/etd/15555

LaRocco SA. (2007). A grounded theory study of socializing men into nursing. Journal of Mens Studies, 15(2):120-9. https://doi.org/10.3149/jms.1502.120

Lee, C., \& Farh, J. L. (2004). Joint effects of group efficacy and gender diversity on group cohesion and performance. Applied Psychology, 53(1), 136-154. https://doi.org/10.1111/j.1464-0597.2004.00164.x

Len-Rios, M. E. (1998). Minority public relations practitioner perceptions. Public Relations Review, 24(4), 535-555. https://doi.org/10.1016/ S0363-8111(99)80116-7.

Levett-Jones, T., Lathlean, J., Maguire, J., \& McMillan, M. (2007). Belongingness: A critique of the concept and implications for nursing education. Nurse Education Today, 27(3), 210218. https://doi.org/10.1016/j.nedt.2006.05.001 
Lewis, K. L., Stout, J. G., Finkelstein, N. D., Pollock, S. J., Miyake, A., Cohen, G. L., \& Ito, T. A. (2017). Fitting in to move forward: Belonging, gender, and persistence in the physical sciences, technology, engineering, and mathematics (pSTEM). Psychology of Women Quarterly, 41(4), 420-436. https://doi.org/10.1177/0361684317720186

Long, N. (2011). Men in public relations: Saving an endangered species. Theses and Dissertations. 73. https://rdw.rowan.edu/etd/73

López-Sáez, M. (1994). Procesos culturales e individuales implicados en la estereotipia de género. Una aproximación empírica a la elección de carrera. Revista de Psicología Social, 9(2), 213-230. https://doi.org/10.1174/021347494763490287

López-Zafra, E. (1999). Liderazgo femenino: Nuevas pautas para un nuevo milenio. In M. A. Bel (Ed.), Ecofeminismo: Un reencuen- tro con la naturaleza (pp. 43-61). España: Servicio de publicaciones de la Universidad de Jaén.

Lupton, B. (2000). Maintaining masculinity: men who do 'women's work'. British Journal of Management, 11, 33-48. https://doi.org/10.1111/1467-8551.11.s1.4

Lynch, O. H. (2002). Humorous communication: Finding a place for humor in communication research. Communication Theory, 12(4), 423-445. https://doi.org/10.1111/j.14682885.2002.tb00277.x

MacWilliams, B.R., Schmidt, B., \& Bleich, M.R. (2013). Men in nursing. American Journal of Nursing, 113, 38-44. doi:10.1097/01. NAJ.0000425746.83731.16

Manning, J. (2017). In vivo coding. In Matthes, J. (Ed.), The international encyclopedia of communication research methods. New York, NY: Wiley-Blackwell. Retrieved from https://doi.org/10.1002/9781118901731.iecrm0270

Ehrlich-Martin, S. (1980). Breaking and entering: policewomen on patrol. Oakland, CA: University of California Press.

Martin, T. (2008). A few good men, PR Week, Retrieved February 26, 2020 from Www.instituteforpr.org/digest_entry/tom_martin_a_few_good_men/.

Master, A., Cheryan, S., \& Meltzoff, A. N. (2016). Computing whether she belongs: Stereotypes undermine girls' interest and sense of belonging in computer science. Journal of Educational Psychology, 108(3), 424. https://doi.org/10.1037/edu0000061

McGrath, C., Palmgren, P. J., \& Liljedahl, M. (2019). Twelve tips for conducting qualitative research interviews. Medical Teacher, 41(9), 1002-1006. 
https://doi.org/10.1080/0142159X.2018.1497149

Meadus, R., \& Twomey, J. (2011). Men student nurses: The nursing education experience. Nursing Forum, 46(4), 269-279. doi:10.1111/j.1744-6198.2011.00239.x.

Meece J.L., Anderman E.M., Anderman L.H. (2006). Classroom goal structure, student motivation, and academic achievement. Annual Review of Psychology, 57, 487-503. https://doi.org/10.1146/annurev.psych.56.091103.070258

Moore, T. E., Griffiths, K., \& Payne, B. (1987). Gender, attitudes towards women, and the appreciation of sexist humor. Sex roles, 16(9-10), 521-531. https://doi.org/10.1007/BF00292486

Morgan, B. B., Salas, E., \& Glickman, A. S. (1993). An analysis of team evolution and maturation. The Journal of General Psychology, 120(3), 277-291. https://doi.org/10.1080/00221309.1993.9711148

Morris L.C. (2007). Power and status in small groups: an analysis of students' verbal and nonverbal behavior and responses to one another, $\mathrm{PhD}$ thesis, University of North Carolina-Chapel Hill.

Muturi, N., \& Zhu, G. (2019). Students' Perceptions of Diversity Issues in Public Relations Practice. Journal of Public Relations Education, 5(2), 75-104.

National Science Foundation. (2009). National Center for Science and Engineering Statistics, special tabulations of U.S. Department of Education, National Center for Education Statistics, Integrated Postsecondary Education Data System, Completions Survey, unrevised provisional release data, various years.

Oliver, R. (1974). Expectancy theory predictions of salesmen's performance. Journal of Marketing Research, 11, 243-253. https://doi.org/10.1177/002224377401100302

O'Neill, K. (1991). US Public relations evolves to meet society's needs. Public Relations Journal, 47(11), 28.

Orenstein, P. (1994). Schoolgirls: Young Women. Self-esteem, and the Confidence Gap.

Paterson, B.L., Tschikota, S., Crawford, M., Saydak, M., Venkatesh, P., \& Aronowitz, T. (1996). Learning to care: Gender issues for male nursing students. Canadian Journal of Nursing Research, 28, 25-39.

Peters, S., \& Froehlich, R. (2006). Women's surge towards PR agencies: The role of 'new' 
gender stereotypes and the organizational context. Conference Papers -- International Communication Association, 1-28.

Place, K., \& Vardeman-Winter, J. (2018). Where are the women? An examination of research on women and leadership in public relations. Public Relations Review, 44(1), 265-173. doi.org/10.1016/j.pubrev.2017.10.005.

Pompper, D., \& Jung, T. (2013). "Outnumbered yet still on top, but for how long?" theorizing about men working in the feminized field of public relations. Public Relations Review, 39(5), 497-497. doi:10.1016/j.pubrev.2013.08.007

Posselt, J. R., \& Lipson, S. K. (2016). Competition, anxiety, and depression in the college classroom: Variations by student identity and field of study. Journal of College Student Development, 57(8), 973-989. https://doi.org/10.1353/csd.2016.0094

PRSSA (n.d.). About PRSSA. Retrieved February 26, 2020 from http://prssa.prsa.org/about-prssa/.

PR Week (2010). (2010). Salary Survey. Retrieved February 26, 2020 from http://www.prweekus.com/salary-survey-2010-the-new-normal/article/164435/.

Qiu, J., \& Muturi, N. (2016). Asian American Public Relations Practitioners' Perspectives on Diversity. Howard Journal of Communications, 27(3), 236-249. https://doi.org/10.1080/10646175.2016.1172527

Rajacich, D., Kane, D., Williston, C., \& Cameron, S. (2013). If they do call you a nurse, it is always a "male nurse": Experiences of men in the nursing profession. Nursing Forum, 48(1), 71-80. https://doi.org/10.1111/nuf.12008

Research Methodology. Research Limitations. (n.d.). Retrieved on April 8, 2020 from https://research-methodology.net/research-methods/research-limitations/.

Reskin, B. F., \& Roos, P. A. (1990). Job queues, gender queues: explaining women's inroads into male occupations (Ser. Women in the political economy). Philadelphia, PA: Temple University Press.

Ridgeway, C. L., \& Erickson, K. G. (2000). Creating and spreading status beliefs. American Journal of Sociology, 106(3), 579-615. https://doi.org/10.1086/318966

Rocca, K. A. (2010). Student participation in the college classroom: An extended multidisciplinary literature review. Communication Education, 59(2), 185-213. https://doi.org/10.1080/03634520903505936 
Rogelberg, S. G., \& Rumery, S. M. (1996). “Gender diversity, team decision quality, time on task, and interpersonal cohesion." Small Group Research, 27(1):79-90. https://doi.org/10.1177/1046496496271004

Roseth, C. J., Johnson, D. W., \& Johnson, R. T. (2008). Promoting early adolescents’ achievement and peer relationships: the effects of cooperative, competitive and individualistic goal structure. Psychological Bulletin, 134, 223-246. doi:10.1037/00332909.134.2.223.https://doi.org/10.1037/0033-2909.134.2.223

Ryan, K. M., King, E. B., Adis, C., Gulick, L. M., Peddie, C., \& Hargraves, R. (2012). Exploring the asymmetrical effects of gender tokenism on supervisor-subordinate relationships. Journal of Applied Social Psychology, 42, E56-E102. https://doi.org/10.1111/j.15591816.2012.01025.x

Tam, S., Dozier, D.M., Lauzen, M., \& Real, M. (1995). Impact of superior-subordinate gender on the career advancement of public relations practitioners. Journal of Public Relations Research, 7(4) 259-272. https://doi.org/10.1207/s1532754xjprr0704_02

U.S. Bureau of Labor Statistics. (2019). Labor Force Statistics from the Current Population Survey: Household Data Annual Averages. Retrieved 2 February, 2019 from https://www.bls.gov/cps/cpsaat11.htm.

Sanjek (Ed.), Fieldnotes: The making of anthropology (pp. 3-33). Ithaca, NY: Cornell University Press.

Sanjek (Ed.), Fieldnotes: The making of anthropology (pp. 3-33). Ithaca, NY: Cornell University Press.

Sayman, D.M. (2014). Fighting the trauma demons: What men in nursing want you to know. Nursing Forum, 50, 9-19. doi:10.1111/nuf.12073. https://doi.org/10.1111/nuf.12073

Sax, L. J. (1996). The dynamics of "tokenism": How college students are affected by the proportion of women in their major. Research in Higher Education, 37(4), 389-425. https://doi.org/10.1007/BF01730108

Sedgwick, M., \& Kellett, P. (2015). Exploring masculinity and marginalization of male undergraduate nursing students' experience of belonging during clinical experiences. The Journal of Nursing Education, 54(3), 121-9. doi:10.3928/01484834-20150218-15.

Seron, C., Silbey, S., Cech, E., \& Rubineau, B. (2018). "I am Not a Feminist, but...”: Hegemony 
of a Meritocratic Ideology and the Limits of Critique Among Women in Engineering. Work and Occupations, 45(2), 131-167. https://doi.org/10.1177/0730888418759774

Seymour, E., \& Hewitt, N. M. (1997). Talking about leaving: Why undergraduates leave the sciences. Boulder, CO: Westview.

Seymour, E. (1995). The loss of women from science, mathematics, and engineering undergraduate majors: An explanatory account. Science Education, 79, 437-473.

Sha, B., \& Toth, E. (2005). Future professionals' perceptions of work, life, and gender issues in public relations. Public Relations Review, 31(1), 93-99.

doi:10.1016/j.pubrev.2004.09.004. https://doi.org/10.1002/sce.3730790406

Shah, A. (2015). Why aren't there more female CEOs in PR? The Holmes Report. Article, http://www.holmesreport.com/long-reads/article/why-aren't-there-more-female-ceos-inpr.

Smith, R. F. (1987). A comparison of career attitudes of news editorial and Ad-PR students. Journalism Quarterly, 64(2), 555-559. https://doi.org/10.1177/107769908706400239

Smith, G. (2005). Commentary: A few good men: Gender balance in the Western Australian public relations industry. PRism, 3. http://praxis.massey.ac.nz

Stott, A. (2004). Issues in the socialization process of the male student nurse: Implications for retention in undergraduate nursing courses. Nurse Education Today, 24, 91-97. doi:10.1016/j.nedt.2003.09.005.

Stott, A. (2007). Exploring factors affecting attrition of male students from an undergraduate nursing course: A qualitative study. Nurse Education Today, 27, 325-332. doi:10.1016/j.nedt.2006.05.013.

Strauss, A., \& Corbin, J. (1994). Grounded theory methodology. In N. Denzin \& Y. Lincoln (Eds.), Handbook of Qualitative Research (pp. 273-285). Thousand Oaks, CA: Sage.

Tosh-Kennedy, T. (2007). Increasing the numbers. The Canadian Nurse, 103(2), 17. Retrieved from

http://www.libproxy.wvu.edu/login?url=https://search.proquest.com/docview/232040055 ?accountid $=2837$

Toth, E. L., Aldoory, L., \& Sha, B.L. (2006). Emerging trends: 24/7 PR mixes work and life. Oct. 11, Unpublished report of the committee on work, life and gender issues to the public relations society of America national board. 
Tuchman, G. (1979). Women's depiction by the mass media. Signs, 4(3), 528-542. https://doi.org/10.1086/493636

USC Libraries (n.d.). Limitations of the study. Retrieved on 1 April 2020 from https://libguides.usc.edu/writingguide/limitations

Vardeman-Winter, J., \& Place, K. R. (2017). Still a lily-white field of women: The state of workforce diversity in public relations practice and research. Public Relations Review, 43(2), 326-336. doi.org/10.1016/j.pubrev.2017.01.004

Wang, M. T., \& Degol, J. L. (2017). Gender gap in science, technology, engineering, and mathematics (STEM): Current knowledge, implications for practice, policy, and future directions. Educational psychology review, 29(1), 119-140. https://doi.org/10.1007/s10648-015-9355-x

Watson, T. (Ed.). (2016). North American Perspectives on the Development of Public Relations: Other Voices. New York, NY: Springer. https://doi.org/10.1057/978-1-349-95044-7

Waymer, D., Brown, K. A., Baker, K., \& Fears, L. (2018). Socialization and pre-career development of public relations professionals via the undergraduate curriculum. Communication Teacher, 32(2), 117-130. https://doi.org/10.1080/17404622.2017.1372590

Wilson, G., (2005). The experience of males entering nursing: a phenomenological analysis of professionally enhancing factors and barriers. Contemporary Nurse, 20(2), 221-233. https://doi.org/10.5172/conu.20.2.221

Witz, A. (1992). Professions and Patriarchy. Routledge, London. https://doi.org/10.4324/9780203167786_chapter_2

Wright, D. K., \& Flynn, T., (2017). Public Relations Education and the Development of Professionalization in Canada and the USA. In Tom Watson (Ed) North American Perspectives on the Development of Public Relations (pp. 51-64). London: Palgrave Macmillan.

https://doi.org/10.1057/978-1-349-95044-7_5

Wrigley, B. (2005). What's the buzz: The Queen Bee Syndrome in public relations. Paper presented at International Communication Association 55 ${ }^{\text {th }}$ Annual Conference. May 2630, 2005, New York, NY.

Yoder, J. D. (1991). Rethinking tokenism: Looking beyond numbers. Gender \& Society, 5(2), 
178-192. https://doi.org/10.1177/089124391005002003

Zimmer, L. (1988). Tokenism and women in the workplace: The limits of gender-neutral theory. Social Problems, 35(1), 64-77 https://doi.org/10.2307/800667 


\section{APPENDIX A \\ INTERVIEW PROTOCOL}

\section{Overall Research Aims:}

1. How does being a gender minority status impact male public relations students social learning outcomes in the upper-level public relations classroom?

2. How does the gender majority status impact females social learning outcomes in the upper-level public relations classroom?

3. How is this similar or different from other single-gender dominant programs?

\section{Quantitative Script and Questions}

\section{[Beginning in-depth interview introduction]}

Thank you for taking time to schedule this meeting. This research is a part of my Master of Science in Journalism degree requirement. This study will take approximately 20-30 minutes of your time and will explore your social experiences interacting with your instructor and peers within the upper-level public relations classroom.

It will consist of a conversation that I will record and transcribe, being sure to omit any personally identifiable information such as your name or any other specifics that might allow a reader to identify you if you so desire. The responses will be kept completely confidential to the extent allowed by law, and the audio recordings will be destroyed after I transcribe them.

Remember, your participation is voluntary. If you do not feel comfortable answering a question, we will skip it and precede to the next question. You can stop the interview at any time.

Before we begin, do I have permission to record this interview?

[Wait until participant states if they choose to begin the interview recording]

Thank you for reading, signing the consent form, and allowing me to record this interview. This interview will explore your experiences interacting with your instructor and peers within an upper-level public relations classroom.

\section{[End of in-depth interview introduction]}

\section{[Beginning of in-depth interview questions]}




\section{Central Questions:}

\section{Role Strain Dimension}

1. Do you feel like you have to work harder because your a male in a predominately female in a upper-level public relations classroom? Why?

\section{Male Follow Up Questions:}

-In completing course assignments, do you feel like you are held to the same academic expectations as your female peers? Why?

-How does your instructor address your praise you for your hard work? Your peers?

-Within the upper-level public relations classroom, who do you reach out to if you are struggling in completing course assignments?

2. Do you feel like you have to work harder because your a female in a predominately female in a upper-level public relations classroom? Why?

\section{Female Follow Up questions:}

-In completing course assignments, do you feel like you are held to the same academic expectations as your male peers?

-How does your instructor address your praise you for your hard work? Your peers?

-Within the upper-level public relations classroom, who do you reach out to if you are struggling in completing course assignments?

\section{Teamwork Dimension}

3. What role does a male play in group assignments in a predominantly female upper-level classroom?

\section{Male Follow Up Questions:}

-What was your role participating in a predominantly female group?

-How does interacting with female students differ from male students in the group?

-Were there any benefits or disadvantages as a male in the group? How?

-What kind of challenges do you have to overcome as a male in a female-dominant upper-level public relations class?

4. How do female students compare male team members versus an all-female group in an upper-level public relations classroom?

\section{Female Follow Up Questions:}

-What was your role participating in a predominantly female group?

-How does interacting with female students differ from male students in the group?

-Were there any benefits or disadvantages as a female in the group?

-What kind of challenges do you have to overcome as a female in a female-dominant upper-level public relations class? 


\section{Overall Social Environment Dimension}

5. How do males interacting with females in a female dominant public relations upper-level classroom influence the perception of the classroom environment?

\section{Male Follow Up Questions:}

-What is difficult or easy about being a male in a female-dominant upper level public relations classroom?

-Have you ever experienced a time in the classroom where you felt like you were treated differently because you were a male?

-How have your social experiences with your female peers in a female-dominant classroom shaped your perception of the classroom environment? How does this compare to other male students?

6. How do females interacting with females in a female dominant public relations upperlevel classroom influence the perceptions of the classroom environment?

\section{Female Follow Up Questions:}

-What is difficult or easy about being a female in a female-dominant upper level public relations classroom?

-Have you ever experienced a time in the classroom where you felt like you were treated differently because you were a female?

-How have your social experiences with your male peers in a female-dominant classroom shaped your perception of the classroom environment? How does this compare to other female students?

\section{[End of in-depth interview questions]}

\section{[Beginning of in-depth interview outro]}

Thank you for taking time to participate in this interview. Your input was very insightful as we move forward with our research study. In your copy of your consent form, my contact information as well as Principal Investigator Dr. Jasper Fessmann is available. Please refer to the consent form if you have any further questions.

[End of in-depth interview outro] 


\title{
APPENDIX B \\ INFORMED CONSENT
}

WestVirginiaUniversity.

OFFICE OF HUMAN RESEARCH PROTECTION

Flex Consent Form

Version 4-May 2019 Minimal Risk

\author{
Principal Investigator (PI) | Dr. Jasper Colin Fessmann \\ Department \\ Reed College of Media \\ WVU IRB Protocol \# | 1911782791 \\ Study Title \\ Exploring the Challenges of Social Integration Within an Upper-Level \\ Public Relations Classroom
}

Why is this research being done and what is involved?

The purpose of this study is to fulfill MSJ candidate Tabitha Dyer's degree requirement. This study will examine your social experiences interacting with your instructor and peers within an upper-level public relations classroom. You will be asked to complete an in-depth interview and a survey which will take approximately 20-30 minutes to complete.

A total of 24 subjects are expected to participate in this study. There will be no further studies.

Do I have to participate and what are the risks?

You may or may not directly benefit from participating in this research. Participation in this research study is completely voluntary and you are free to withdraw from the research at any time.

This survey and in-depth interview will be discussing your social experiences with your instructor and peers in an upper-level public relations classroom. Participants may experience feelings of anxiety, stress, or low self-esteem if you feel you have negative experiences in the classroom environment. Specifically, you will be asked about your experiences working in teams, your determination and the overall classroom environment.

In addition, there is always the risk of uncommon or previously unknown side effect(s) or event. If you experience these feelings or an unknown side effect, your participation is voluntary and you do not have to answer the question(s).

For information regarding your rights as a participant in research or to talk about the research, contact the WVU Office of Human Research Protection (OHRP) at (304) 293-7073 or by email at IRB@mail.wvu.edu.

Will I be compensated for my participation?

There is no financial compensation for participating in this study. Your data, research results, or any and all other information related to this research study used in this research study may contribute to a new discovery or treatment. In some instances, your data, your research results, or any other information related to this research study, even if identifiers are removed, may be of commercial value and may be sold, patented, or licensed by the investigators and West Virginia University for use in other research or the development of new products. You will not retain any property rights, nor will you share in any money or commercial profit that the investigators, West Virginia University, or their agents may realize. 
What will happen to my research information and data?

Any information about you that is obtained as a result of your participation in this research will be kept as confidential as legally possible. Your research records and test results, just like hospital records, may be subpoenaed by court order or may be inspected by the study sponsor or federal regulatory authorities, without your additional consent. Audiotapes or videotapes will be kept locked up and will be destroyed as soon as possible after the research is finished.

In addition, there are certain instances where the researcher is legally required to give information to the appropriate authorities. These would include mandatory reporting of infectious diseases, mandatory reporting of information about behavior that is imminently dangerous to you or to others, such as suicide, child abuse, etc. In any publications that result from this research, neither your name nor any information from which you might be identified will be published without your consent. In any publications that result from this research, neither your name nor any information from which you might be identified will be published without your consent.

Persons/Organizations Providing the Information

You will provide information about your personal experiences.

Persons/Organizations Receiving the Information

The research site(s) carrying out this study. This includes all study personnel (Principal Investigator Dr. Jasper Fessmann, Co-investigator Tabitha Dyer and Dyer's other thesis committee members (including Dr. Jennifer Harker and Prof. Dana Coester), the members and staff of any Institutional Review Board (IRB) that oversees this research study, and the West Virginia University Office of Human Research Protection and the West Virginia University Office of Sponsored Programs.

The Following Information Will Be Used

New information about you that is created or collected during this study, such as: demographic data, and study forms.

The Information is Being Disclosed for the Following Reasons

Publication of study results (without identifying you).

You may Cancel this Authorization at Any Time by Writing to the Principal Investigator

Jasper Fessmann, Ph.D.

West Virginia University, 1511 University Ave. Room 312, Reed College of Media

PO Box 6010 | Morgantown, WV 26506-6010 
If you cancel this authorization, any information that was collected already for this study cannot be withdrawn. Once information is disclosed, according to this authorization, the recipient may re-disclose it and then the information may no longer be protected by federal regulations.

You have a right to see and make copies of your research records. You will not be able to see or copy your records related to the study until the sponsor has completed all work related to the study. At that time, you may ask to see the study principal investigators files related to your participation in the study and have the study principal investigators correct any information about you that is wrong. This authorization will expire at the end of the study unless you cancel it before that time.

Who can I talk to if I have questions or concerns?

If you have any questions, concerns, or complaints about this research, you can contact Dr. Jasper Fessmann at jasper.fessmann@mail.wvu.edu or by office phone at (304) 293-6568. You can also contact Tabitha Dyer at thd0001@mix.wvu.edu or by mobile at 304-559-3439. For information regarding your rights as a participant in research or to talk about the research, contact the WVU Office of Human Research Protection (OHRP) at (304) 293-7073 or by email at $\underline{\text { IRB@mail.wvu.edu. }}$

Signatures

You have been given the opportunity to ask questions about the research and you have received answers concerning areas you did not understand. Upon signing this form, you will receive a copy.

\section{Participant Signature}

I willingly consent to participate in this research.

Signature of Subject or Subject's Legal Representative

Printed Name Date

\section{Consenting Individual Signature}

The participant has had the opportunity to have questions addressed. The participant willingly agrees to be in the study.

Signature of Person Obtaining Informed Consent

Printed Name Date




\title{
APPENDIX C \\ INSTITUTIONAL REVIEW BOARD APPROVAL
}

\author{
WestVirginiaUniversity. \\ OFFICE OF HUMAN RESEARCH PROTECTIONS \\ 886 Chestnut Ridge Road Morgantown, WV 26506
}

Flex Model Approval

$01 / 30 / 2020$

To: Jasper Fessmann

From: WVU Human Research Protection Program

Protocol Type: NHSR / Flex

Approval Date: 01/30/2020

Submission Type: Initial

Expiration Date: 01/29/2025

Funding: N/A

WVU Protocol \#: 1911782791

Protocol Title: Exploring the Challenges of Social Integration within an Upper-Level Public Relations Classroom

The West Virginia University Institutional Review Board has determined that your submission of protocol 1911782791 qualifies for approval under the WVU Flexibility Review Model.

- FLEX: The review of the above referenced protocol was conducted in accordance with the ethical principles of the Belmont Report. The protocol meets the criteria for approval Flex Model Review because the project does not have federal funding, is considered to be minimal risk, and falls within the guidelines of the WVU Flex Model as of this approval date.

The following documents were reviewed and approved for use as part of this submission. Only the documents listed below may be used in the research. Please access and print the files in the Notes \& Attachments section of your approved protocol.

- IRB_Flex_Dyer.pdf

- IRB_Flex_Class:Email Pitch_Dyer.docx

- IRB_Flex_Quantitative_Qualitative_Dyer.docx

WVU IRB approval of protocol 1911782791 will expire on 01/29/2025. 
If the study is to continue beyond the expiration date, a renewal application should be submitted no later than four (4) weeks prior to the expiration date. It is your responsibility to submit your protocol to the WVU IRB for review.

Once you begin your project, the following apply:

1. Unanticipated, serious adverse events and/or side effect(s) encountered at WVU or an affiliate site that are related to the research must be reported to the WVU IRB within five (5) days using the Notify IRB action in WVU+kc.

2. Any Unanticipated Problem or UPIRTSO or other research related event resulting in new or increased risk of harm to study subjects, occurring at WVU or an affiliate site, must be reported to the WVU IRB within five (5) days using the Notify IRB action in WVU+kc.

3. All research personnel performing tasks related to the research must complete and remain current for the required training as applicable to the protocol referenced above.

4. Only Flex Consent Forms with the WVU+ke watermark may be used to consent participants.

5. The IRB must be notified if there is an increase in risk to participants or if federal funding is awarded to conduct research under this protocol. These modifications must be submitted as an amendment in WVU+kc.

The WVU Human Research Protection Program will be glad to provide assistance to you throughout the research process. Please feel free to contact us by phone at 304.293 .7073 or by email at IRB@mail.wvu.edu.

Sincerely,

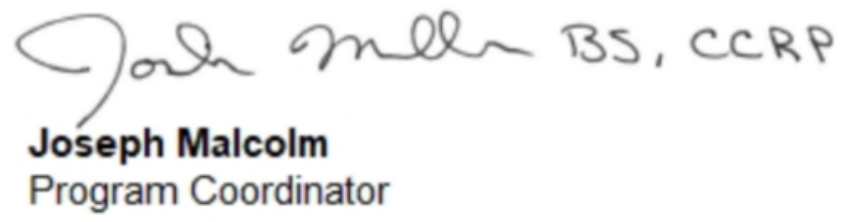


APPENDIX D

OPEN CODES AND THEIR PROPERTIES

\begin{tabular}{|c|c|c|}
\hline Open Code & Properties & Examples \\
\hline $\begin{array}{l}\text { Female-to-Female } \\
\text { Understanding }\end{array}$ & $\begin{array}{l}\text { Emotional understanding, } \\
\text { Mutual understanding, Relate }\end{array}$ & $\begin{array}{l}\text { P3: "they understand how } \\
\text { emotional I can be with } \\
\text { assignments" } \\
\text { P5: "I could relate to them } \\
\text { more" } \\
\text { P6: "girls definitely fall into } \\
\text { more conversations about } \\
\text { mutual things that they have } \\
\text { in common" } \\
\text { P9: "they might have a better } \\
\text { understanding of what I'm } \\
\text { going through" }\end{array}$ \\
\hline Female-to-Female Comfort & $\begin{array}{l}\text { Friendship, Female-dominant, } \\
\text { Easy }\end{array}$ & $\begin{array}{l}\text { P4: "I've built a friendship } \\
\text { with rather than the men" } \\
\text { P5: "I saw so many females" } \\
\text { P7: "it's easier to talk to } \\
\text { females" }\end{array}$ \\
\hline $\begin{array}{l}\text { Female-to-Female } \\
\text { Communication }\end{array}$ & $\begin{array}{l}\text { Communication, Comfort, } \\
\text { Bond }\end{array}$ & $\begin{array}{l}\text { P4: "it's just easier talking to } \\
\text { the women" } \\
\text { P5: "I'm going to be a little } \\
\text { more intimidated" } \\
\text { P6: "girls have that unspoken } \\
\text { bond" }\end{array}$ \\
\hline Organic Gender Segregation & $\begin{array}{l}\text { Same-gender reliance, Same- } \\
\text { gender value, Same-gender } \\
\text { instinct }\end{array}$ & $\begin{array}{l}\text { P3: "females stay with } \\
\text { females and males stay with } \\
\text { males" } \\
\text { P6: "females tend to ask more } \\
\text { females their opinions and } \\
\text { questions" } \\
\text { P7: "it's just kind of } \\
\text { instinctual. I guess for } \\
\text { females to reach out to just to } \\
\text { ask another female" }\end{array}$ \\
\hline $\begin{array}{l}\text { Female-to-Female } \\
\text { Competition }\end{array}$ & $\begin{array}{l}\text { Same page, Equal } \\
\text { opportunity, Group } \\
\text { competition }\end{array}$ & $\begin{array}{l}\text { P6: "I get nervous, maybe I'm } \\
\text { not on the same page as } \\
\text { them" }\end{array}$ \\
\hline
\end{tabular}




\begin{tabular}{|c|c|c|}
\hline & & $\begin{array}{l}\text { P9: "I feel as though we're } \\
\text { more similar on those fronts" } \\
\text { P10: "I would probably feel a } \\
\text { little bit of competition with } \\
\text { them to lead" }\end{array}$ \\
\hline $\begin{array}{l}\text { Female-to-Female } \\
\text { Comparison }\end{array}$ & $\begin{array}{l}\text { Internship opportunities, } \\
\text { Academic expectations, } \\
\text { Negative comparison }\end{array}$ & $\begin{array}{l}\text { P4: "lots of internships or } \\
\text { attention on social media" } \\
\text { P5: "Do I reach those } \\
\text { expectations?" } \\
\text { P6: "comparing themselves to } \\
\text { each other in maybe a } \\
\text { negative light" }\end{array}$ \\
\hline Stand Out as a Female & Outdo, Succeed & $\begin{array}{l}\text { P2: "Oh, you know I can do } \\
\text { better than you," and kind of } \\
\text { one-up you" } \\
\text { P3: "rise above everyone so I } \\
\text { can get that job someday" } \\
\text { P6: "I want to be better than } \\
\text { her" }\end{array}$ \\
\hline Do not Compete with Males & $\begin{array}{l}\text { Male difficulty, Females } \\
\text { envy, Male-to-male } \\
\text { competition, Female- } \\
\text { dominant, Less assertive male }\end{array}$ & $\begin{array}{l}\text { P2: "it's kind of hard for them } \\
\text { to try to be as competitive as } \\
\text { kind of the females" } \\
\text { P4: "women are generally } \\
\text { more envious of each other" } \\
\text { P6: "Whereas I'm sure guys } \\
\text { aren't as jealous of females } \\
\text { work ethic versus the other } \\
\text { guy in their class" } \\
\text { P8: "there are more of us than } \\
\text { there are of them" } \\
\text { P10: "they don't really assert } \\
\text { themselves" }\end{array}$ \\
\hline $\begin{array}{l}\text { Females were Leaders in } \\
\text { Teamwork }\end{array}$ & $\begin{array}{l}\text { Females more likely to lead, } \\
\text { Female leader }\end{array}$ & $\begin{array}{l}\text { P1: "we're always appointed } \\
\text { as the leaders" } \\
\text { P2: "I am the leader in the } \\
\text { group" } \\
\text { P5: "I feel like the females } \\
\text { tend to take on more of the } \\
\text { leader" } \\
\text { P6: "the females are more of } \\
\text { the leaders" } \\
\text { P8: "I was the team leader" }\end{array}$ \\
\hline
\end{tabular}




\begin{tabular}{|c|c|c|}
\hline $\begin{array}{l}\text { Males were not Interested in } \\
\text { Leadership Roles }\end{array}$ & $\begin{array}{l}\text { No male leader, Lack of male } \\
\text { interest }\end{array}$ & $\begin{array}{l}\text { P5: "honestly, no." } \\
\text { P11: "don't really want to } \\
\text { take the leadership role" } \\
\text { P12: "I don't think I wanted } \\
\text { to lead" }\end{array}$ \\
\hline $\begin{array}{l}\text { Gendered Communication } \\
\text { Receptiveness }\end{array}$ & $\begin{array}{l}\text { Female-to-female agreement, } \\
\text { Lack of male dependence }\end{array}$ & $\begin{array}{l}\text { P4: "they didn't really rely on } \\
\text { him as much" } \\
\text { P6: "Shot down type of thing" } \\
\text { P7: "we definitely respond } \\
\text { better to the female" } \\
\text { P8: "everybody else would } \\
\text { agree with me" }\end{array}$ \\
\hline Contribute less in Groupwork & $\begin{array}{l}\text { Lack of attention, Females } \\
\text { work harder, Males contribute } \\
\text { less }\end{array}$ & $\begin{array}{l}\text { P2: "Hmm, they're not really } \\
\text { all there." } \\
\text { P7: "just sitting and listening } \\
\text { more so than talking. I think } \\
\text { people aren't expecting guys } \\
\text { to say as much" } \\
\text { P9: "Male's just going to } \\
\text { coast along and go along with } \\
\text { what the females are doing" } \\
\text { P10: "They don't really have } \\
\text { to try very hard." } \\
\text { P12: "I would just listen. I } \\
\text { didn't know what to say" }\end{array}$ \\
\hline $\begin{array}{l}\text { Reminded to Complete } \\
\text { Coursework }\end{array}$ & $\begin{array}{l}\text { Did not complete } \\
\text { assignments, Wanted to pass, } \\
\text { Less willing, Academic slack }\end{array}$ & $\begin{array}{l}\text { P3: "We just had to kept } \\
\text { hounding him to do stuff." } \\
\text { P5: "Okay, I have a C, I'm } \\
\text { passing, that's good enough } \\
\text { for me" } \\
\text { P7: "I just feel like girls are } \\
\text { more willing to just do it" } \\
\text { P12: "I have occasion to slack } \\
\text { off to do things to the last } \\
\text { minute" }\end{array}$ \\
\hline Less effort than Females & $\begin{array}{l}\text { Last minute, Bare-minimum, } \\
\text { Less motivated }\end{array}$ & $\begin{array}{l}\text { P2: "there's a consistent } \\
\text { procrastination with boys" } \\
\text { P5: "they would do it, be } \\
\text { done with it and not really try } \\
\text { to go above and do anything } \\
\text { else"" } \\
\text { P7:"guys don't have as much }\end{array}$ \\
\hline
\end{tabular}




\begin{tabular}{|c|c|c|}
\hline & & $\begin{array}{l}\text { motivation as girls" } \\
\text { P11: "take the backseat like I } \\
\text { said and just do my part and } \\
\text { help them" }\end{array}$ \\
\hline $\begin{array}{l}\text { Lack of Experience with Male } \\
\text { Peers }\end{array}$ & $\begin{array}{l}\text { Female-dominant classroom, } \\
\text { lack of males presence }\end{array}$ & $\begin{array}{l}\text { P1: "one PR class there was } \\
\text { one or two guys" } \\
\text { P3: "more females than males } \\
\text { "“ } \\
\text { P7: "mostly girls and there } \\
\text { are a few guys" } \\
\text { P11: "there aren't that many } \\
\text { males in the PR classrooms" } \\
\text { P13: "I've worked with more } \\
\text { females" }\end{array}$ \\
\hline Males Entertainment & $\begin{array}{l}\text { Jokes, Commentary, } \\
\text { Entertainment }\end{array}$ & $\begin{array}{l}\text { P4: "Making jokes and } \\
\text { laughing really loudly" } \\
\text { P6: "just commentary to } \\
\text { lighten the mood" } \\
\text { P12: "I actually could } \\
\text { entertain the class with my } \\
\text { sense humor" }\end{array}$ \\
\hline $\begin{array}{l}\text { Classroom Context for } \\
\text { Humor }\end{array}$ & $\begin{array}{l}\text { In-class videos, Context, } \\
\text { Improvise, Discussions }\end{array}$ & $\begin{array}{l}\text { P6: "if we're watching a } \\
\text { video, "What is that girl doing } \\
\text { in the video?" } \\
\text { P8: "As long as it fits the } \\
\text { context of what we're talking } \\
\text { about" } \\
\text { P12: "fit the spot or jokes that } \\
\text { just came out of nowhere" } \\
\text { P13: "people laugh and that's } \\
\text { in the realm of what we're } \\
\text { talking about" }\end{array}$ \\
\hline $\begin{array}{l}\text { Male Jokes Received } \\
\text { Negatively }\end{array}$ & $\begin{array}{l}\text { Annoyed, To be heard, } \\
\text { Impassive, No negative } \\
\text { reactions }\end{array}$ & $\begin{array}{l}\text { P4: "most of the time they'd } \\
\text { just be annoyed by it" } \\
\text { P6: "You obviously just } \\
\text { wanted your voice to be } \\
\text { heard" } \\
\text { P7: "females don't care" } \\
\text { P12: "I feel like there wasn't } \\
\text { any negative reactions." }\end{array}$ \\
\hline Sibling of Opposite Sex & Upbringing, Older Siblings & P8: "growing up my brother \\
\hline
\end{tabular}




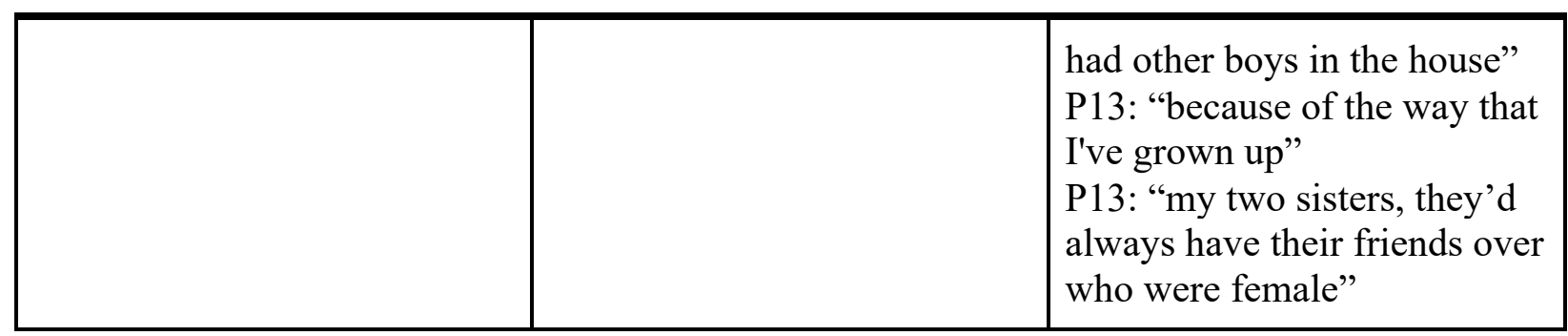

OPEN CODES AND THEIR PROPERTIES (CONT.)

\begin{tabular}{|l|l|l|}
\hline Open Code & Properties & Examples \\
\hline $\begin{array}{l}\text { Level of Comfort with } \\
\text { Opposite Sex }\end{array}$ & Relate, Comfort & $\begin{array}{l}\text { P2: "I can relate to him a little } \\
\text { bit better" } \\
\text { P8: "I think that contributed } \\
\text { to my comfort level" } \\
\text { P13: "made me much more } \\
\text { comfortable" }\end{array}$ \\
\hline
\end{tabular}

